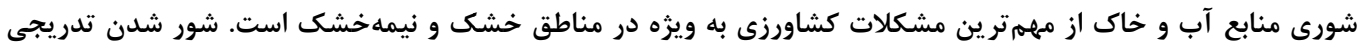

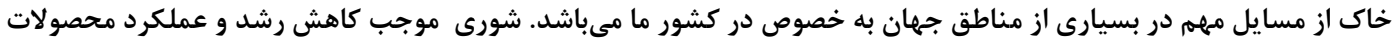

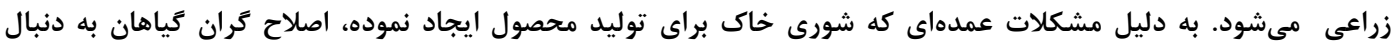

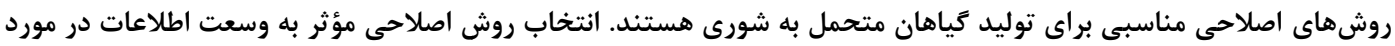

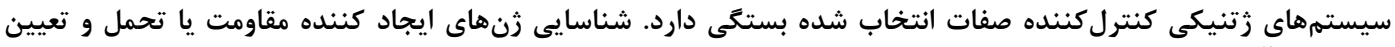

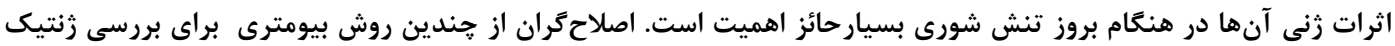

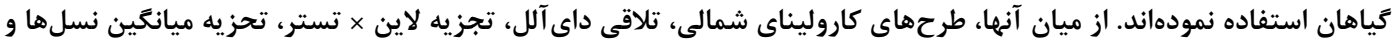

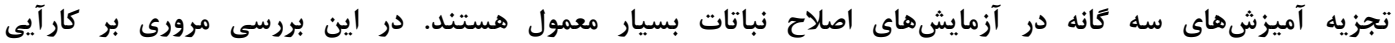

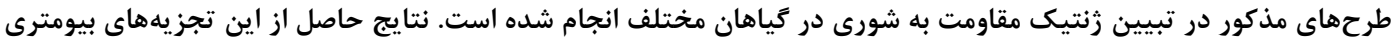

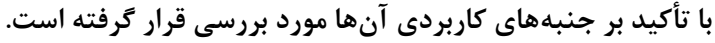

وازههاى كليدى: ترييل تست كراس، مقاومت به شورى، داى آلل، طرحهاى كاروليناى شمالى، تحزيه ميانگين نسلها، تجزيه لاين × تستر

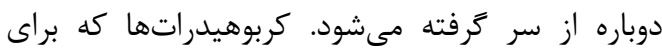

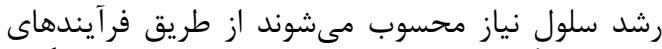

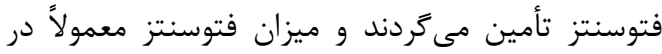

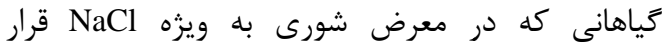

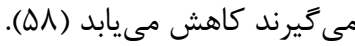

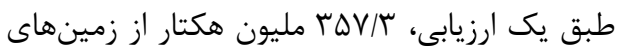

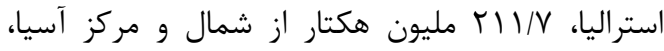

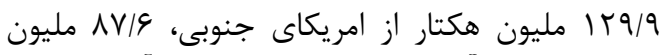

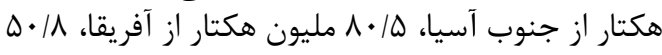

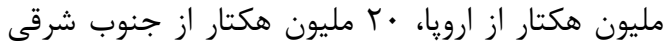

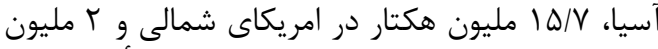

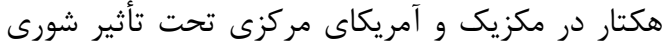

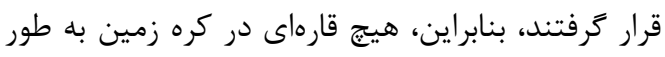

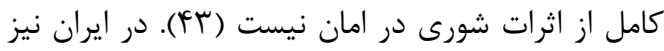

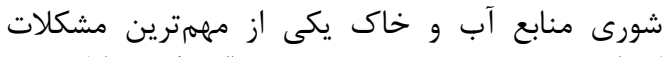

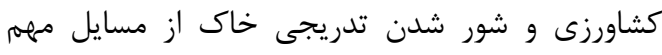

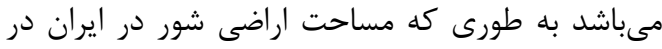

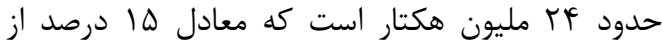
اراضى كشور است.

شورى يك تهديد جدى بر براى دست إيابى به يتانسيل

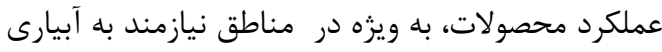

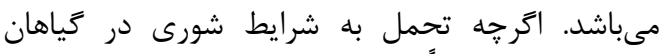

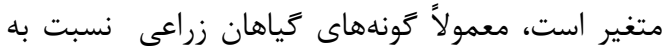

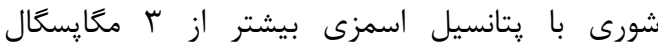

شورى آبهاى آبيارى و خاكهاى كشاورزى به كند عنوان مهمترين فاكتور محدود كننده رشياري رشد محصولات

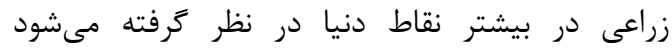

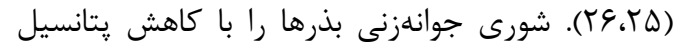

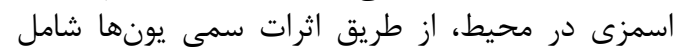

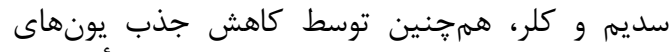

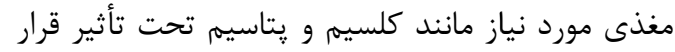

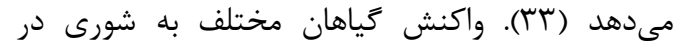

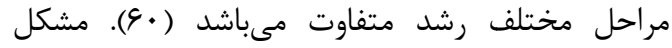

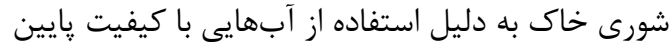

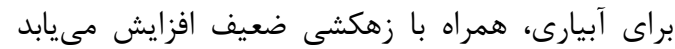

شورى فاكتور مهرم و محدودكننده رشد زياه و وخ

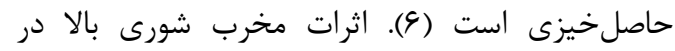

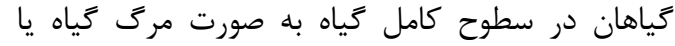
كاهش در توليد و بارورى مياهب دراشد. بسيارى از كياهان

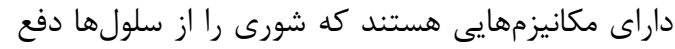

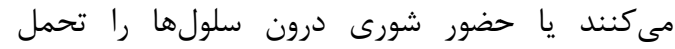

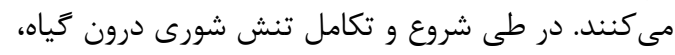

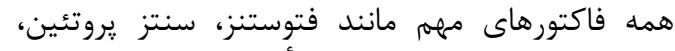

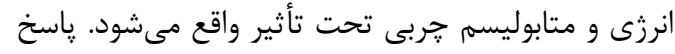

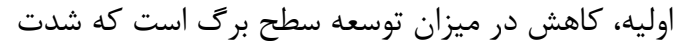

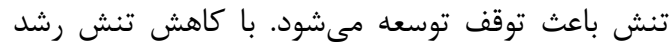


و و III تجزيه ميانخين نسلها و تجزيه لاين × تستر اشاره كرد

زنتيك تحمل به شورى (ب).

تلاشهاى اوليه براى ارزيابى توارث تحمل به به شورى

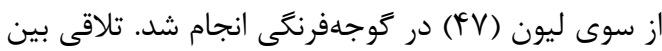

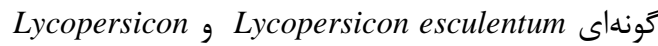
عimpinellifolium

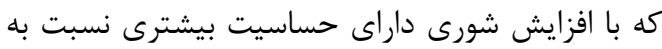

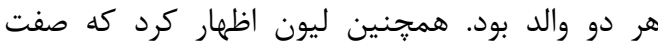

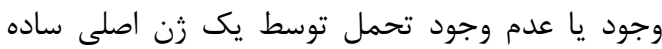

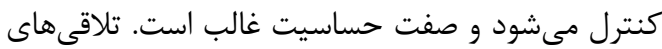

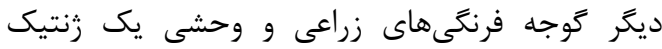

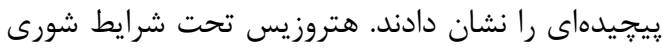

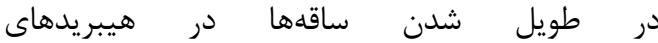
نمايان شد كه از سه گونه وحشى د.esculentum

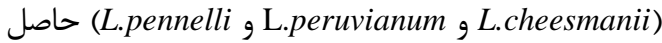
شده بود (r)). طويل شدن ساقه يك صفت غالب است

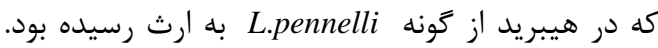

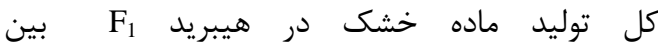
L.pennelli و L.esculentum

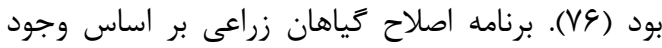

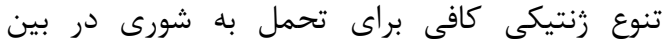

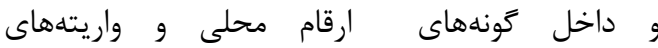

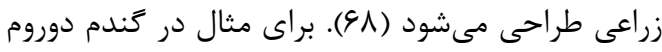
(Triticum durum L.)

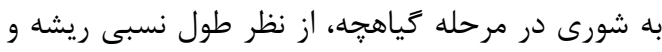

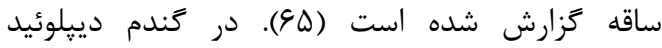
نيز تنوع زنتيكى كافى براى (Aegilpos speltoides L.)

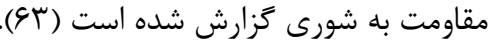

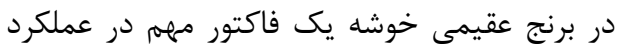

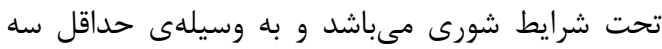

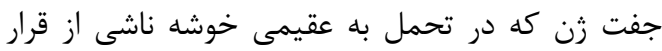

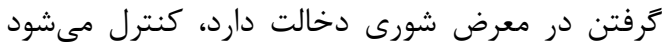

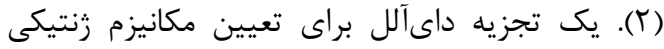

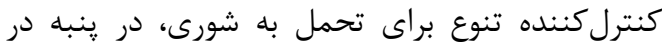

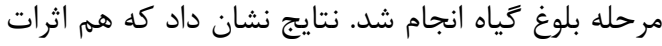

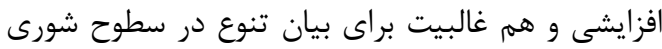

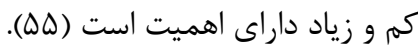

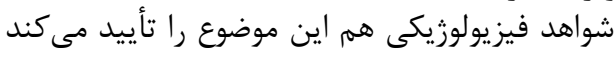

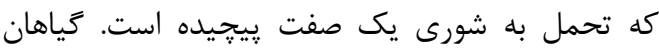

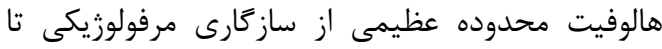

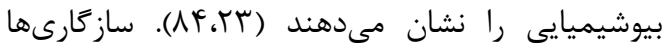

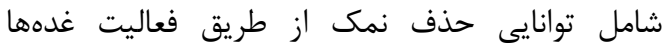

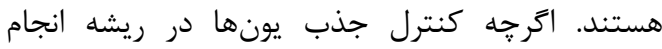

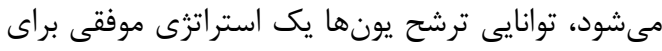

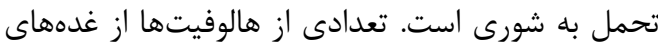

حساس هستند. تلاشهايى براى بهبود تحمل به شورى

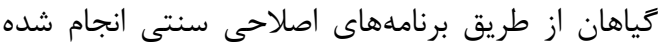

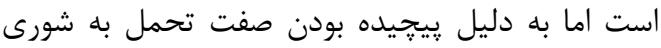

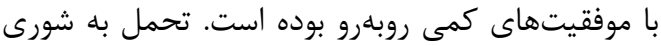

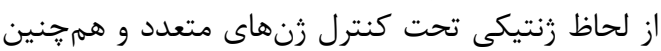

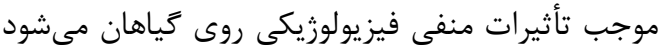

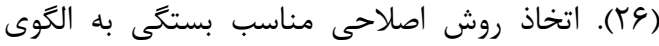

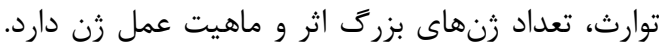

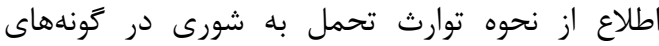

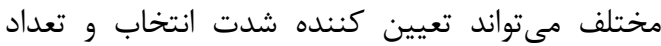

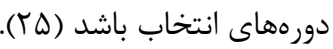
به دليل اين كه مقاومت به شورى يك صفت صفت كمى إنى

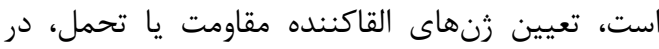

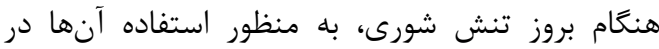

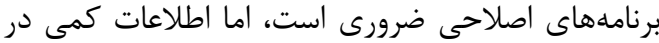

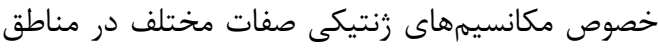

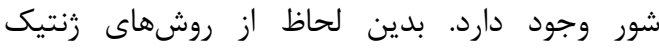

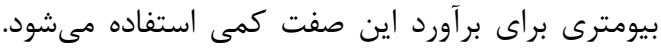

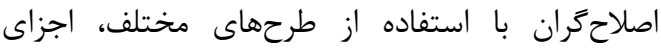

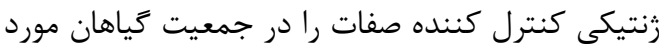

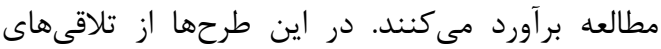

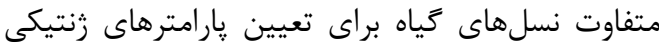

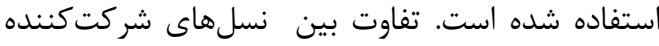

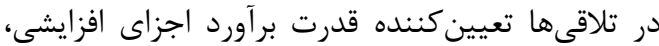

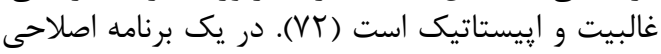

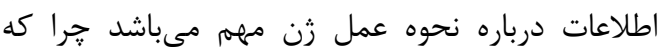

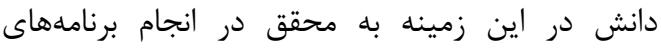

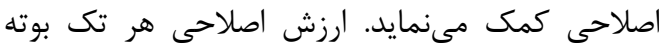

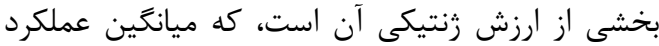

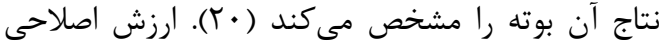

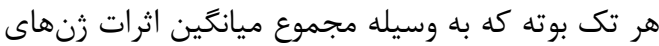

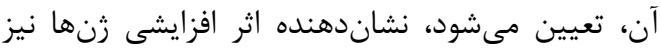

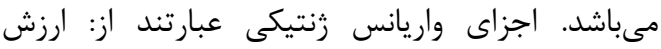

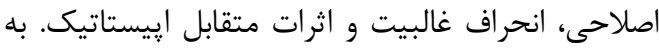

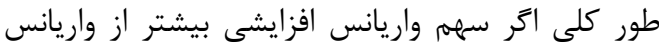

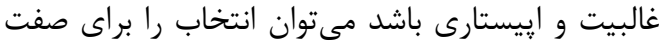

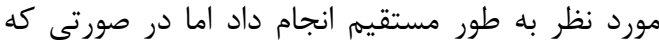

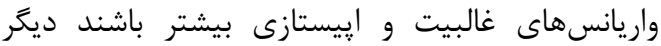

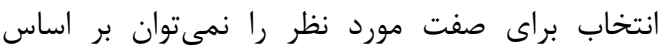

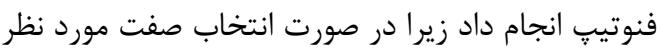

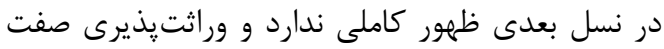

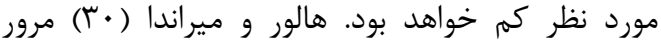

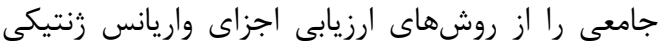

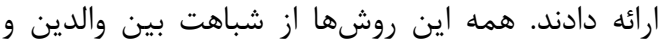

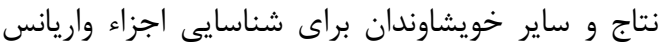

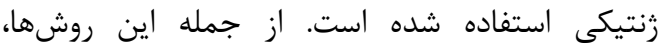

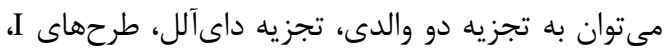


مىشوند داراى اهميت بالايى مىباشند. در اين مرحله

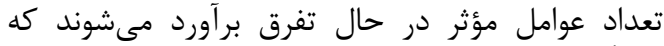

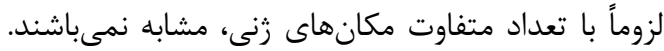

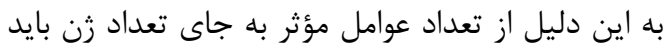

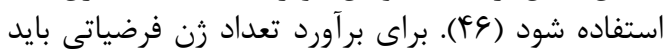

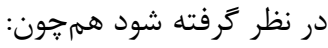

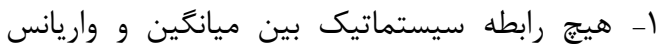
وجود نداشته باشد.

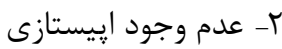

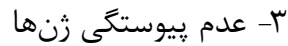

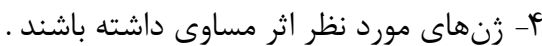

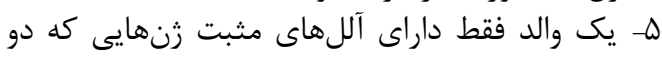

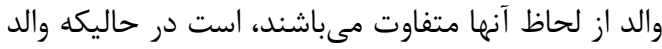

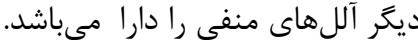

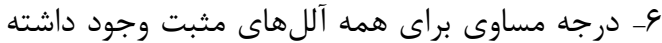

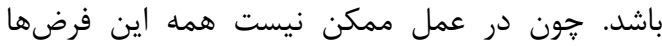

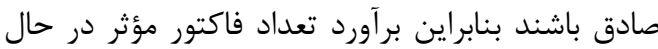

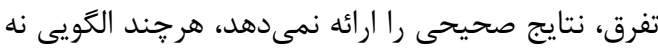

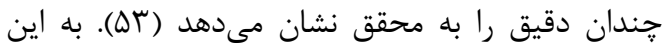

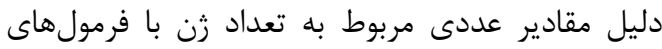

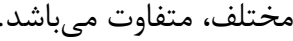

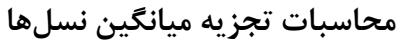
در ابتدا نسلهاى والدينى (PC BC2

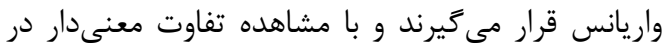

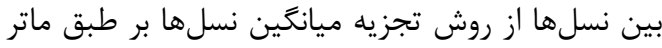

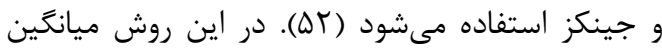

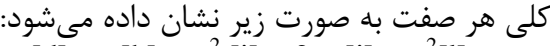
$\mathrm{Y}=\mathrm{m}+\alpha[\mathrm{d}]+\beta[\mathrm{h}]+\alpha^{2}[\mathrm{i}]+2 \alpha \beta[\mathrm{j}]+\beta^{2}[\mathrm{l}]$

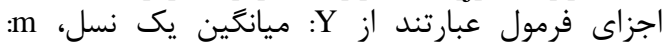

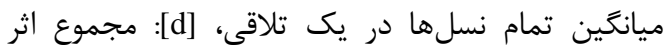

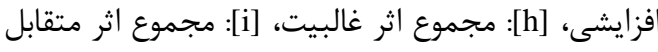

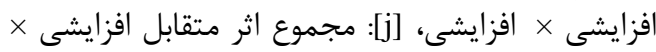

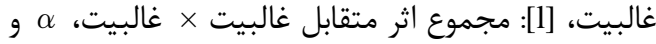
رن زنتيكى مدل هستند.

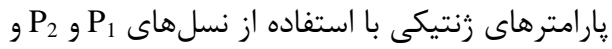

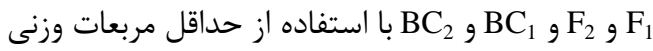
(Weighted Least Square)

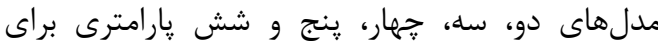

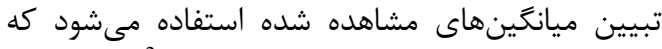

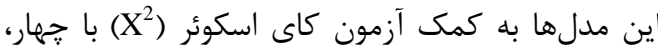

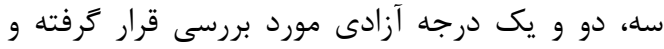

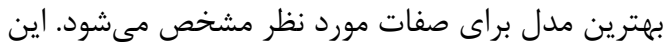

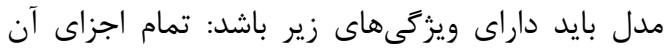

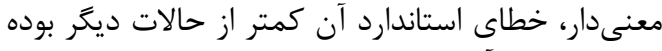

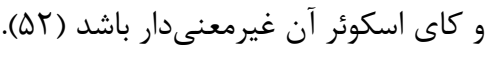

ترشحى نمك در حذف يونهاى اضافى از برگهايشان

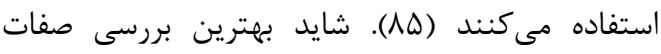

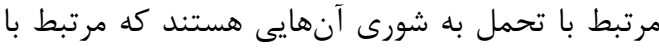

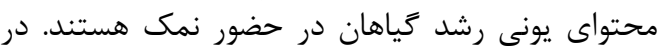

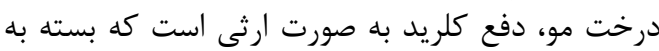

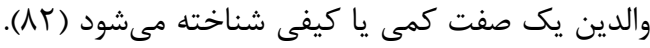

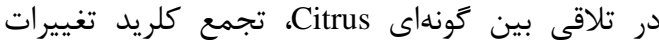

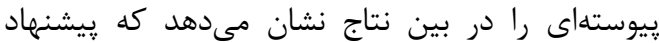

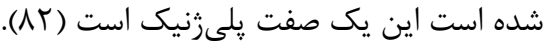

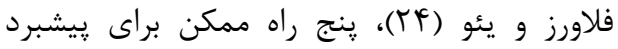

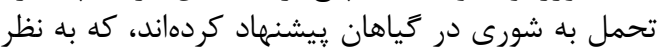

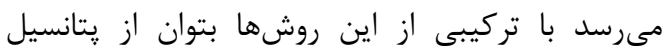

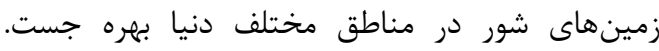

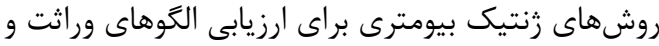

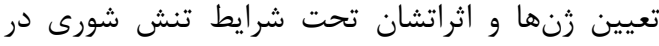

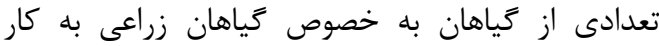

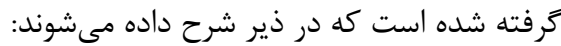

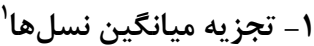

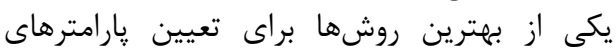

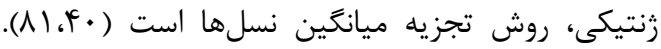

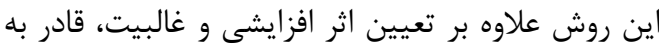

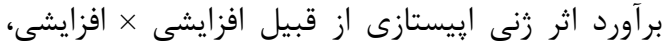

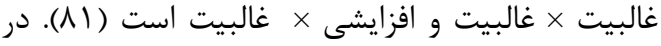

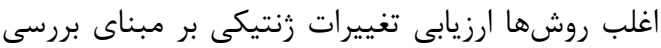

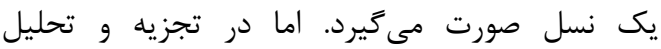

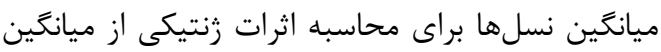

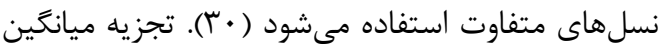

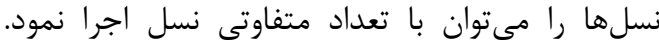

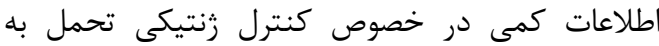

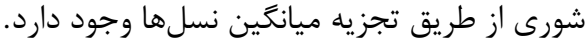

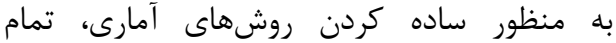

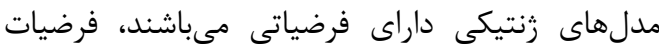

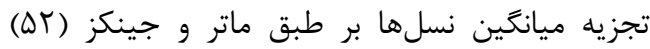

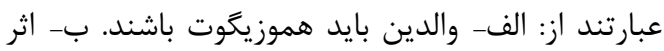

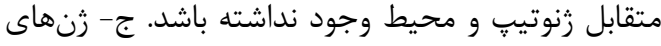

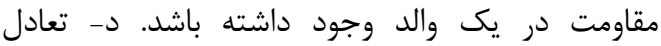

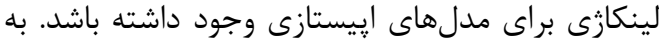

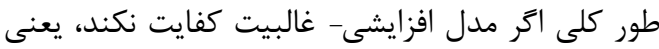

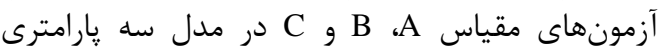

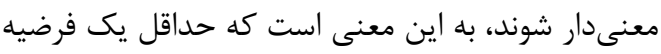

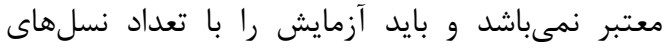

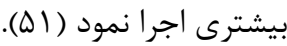

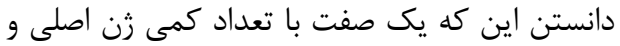

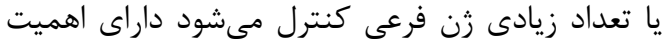

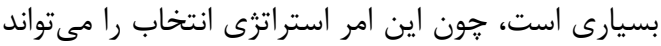

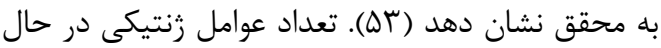

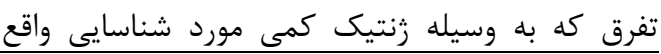




$$
\text { rV. }
$$

بر اساس روش ماتر وجينكز اجزاى تنوع از شش نسل طبق فرمولهاى زير محاسبه مىشوند روند

$\mathrm{EW}=1 / 4\left(\mathrm{~V}_{\mathrm{P} 1}+\mathrm{V}_{\mathrm{P} 2}+2 \mathrm{~V}_{\mathrm{F} 1}\right)$ جزء غيرقابل توارث تنوع:

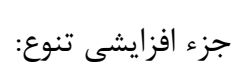

$$
\begin{aligned}
& \mathrm{D}=4 \mathrm{~V}_{\mathrm{F} 2}-2\left(\mathrm{~V}_{\mathrm{BC} 1}+\mathrm{V}_{\mathrm{BC} 2}\right) \\
& \mathrm{H}=4\left(\mathrm{~V}_{\mathrm{BC} 1}+\mathrm{V}_{\mathrm{BC} 2}-\mathrm{V}_{\mathrm{F} 2}-\mathrm{E}_{\mathrm{W}}\right)
\end{aligned}
$$

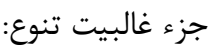

$$
\begin{aligned}
& \mathrm{F}=\left(\mathrm{V}_{\mathrm{BC} 1}-\mathrm{V}_{\mathrm{BC} 2}\right) \\
& \text { همبستخى d و h روى تمام مكانهاى زنى: } \\
& \text { براى تعيين وراثتيذيرى عمومى (Hb) از فرمول هاى } \\
& \text { زير استفاده مىشود: }
\end{aligned}
$$

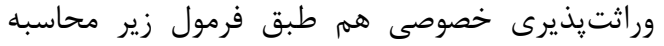

$$
\begin{aligned}
& \mathrm{h}_{\mathrm{n}}^{2}=\left[2 \mathrm{~V}_{\mathrm{F} 2}-\left(\mathrm{V}_{\mathrm{BC} 1}+\mathrm{V}_{\mathrm{BC} 2}\right)\right] / \mathrm{V}_{\mathrm{F} 2}
\end{aligned}
$$

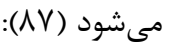

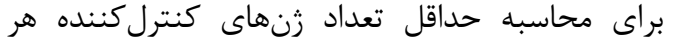

$$
\begin{aligned}
& \text { صفت از فرمول هاى زير استفاده مىشود (r^): } \\
& \mathrm{h}_{\mathrm{b}}^{2}=\left[\mathrm{V}_{\mathrm{F} 2}-\left(\mathrm{V}_{\mathrm{P} 1} \times \mathrm{V}_{\mathrm{P} 2}\right)^{1 / 2}\right] / \mathrm{V}_{\mathrm{F} 2} \\
& \mathrm{~h}_{\mathrm{b}}^{2}=\left[\mathrm{V}_{\mathrm{F} 2^{-}}\left(\mathrm{V}_{\mathrm{P} 1} \times \mathrm{V}_{\mathrm{P} 2}+\mathrm{V}_{\mathrm{F} 1}\right) / 3\right] / \mathrm{V}_{\mathrm{F} 2} \\
& \mathrm{~h}_{\mathrm{b}}^{2}=\left[\mathrm{V}_{\mathrm{F} 2}-\left(\mathrm{V}_{\mathrm{P} 1} \times \mathrm{V}_{\mathrm{P} 2} \times \mathrm{V}_{\mathrm{F} 1}\right)^{1 / 3}\right] / \mathrm{V}^{\mathrm{F} 2} \\
& \mathrm{~h}_{\mathrm{b}}^{2}=\left[\mathrm{V}_{\mathrm{F} 2^{-}}\left(\mathrm{V}_{\mathrm{P} 1}+\mathrm{V}_{\mathrm{P} 2}\right) / 2\right] / \mathrm{V}_{\mathrm{F} 2} \\
& \mathrm{~h}_{\mathrm{b}}^{\llcorner}=\left[\mathrm{V}_{\mathrm{F} 2^{-}}\left(\mathrm{V}_{\mathrm{P} 1}+\mathrm{V}_{\mathrm{P} 2}+2 \mathrm{~V}_{\mathrm{F} 1}\right) / 4\right] / \mathrm{V}_{\mathrm{F} 2} \\
& \mathrm{n}=\left(\mathrm{P}^{-}{ }_{\mathrm{P} 1}\right) 2 /\left[8\left(\sigma_{\mathrm{F} 2}^{2}-\sigma_{\mathrm{F} 1}^{2}\right)\right. \\
& \mathrm{n}=\left(\mathrm{P}^{-}{ }_{\mathrm{P} 1}\right) 2 /\left\{8\left(\left[\sigma_{\mathrm{F} 2^{-}}^{2}\left(0.5 \sigma_{\mathrm{F} 1}^{2}+0.25 \sigma_{\mathrm{P} 1}^{2}+0.25 \sigma_{\mathrm{P} 2}^{2}\right)\right]\right\}\right. \\
& \mathrm{n}=\left({\mathrm{P} 22^{-} \mathrm{P} 1}\right) 2 /\left\{8\left(\sigma_{\mathrm{BC} 1}^{2}+\sigma^{2}{ }_{\mathrm{BC} 2}\right)-\left(\sigma_{\mathrm{F} 1}^{2}+0.5 \sigma_{\mathrm{P} 1}^{2}+0.5 \sigma_{\mathrm{P} 2}^{2}\right)\right\} \\
& \mathrm{n}=\left(\mathrm{F} 1_{\mathrm{p} 1}\right) 2 /\left\{4\left[\sigma_{\mathrm{BC} 1}^{2}-0 / 5\left(\sigma_{\mathrm{F} 2}^{2}+\sigma_{\mathrm{P} 1}^{2}\right)\right]\right\} \\
& \mathrm{n}=\left(\mathrm{P} 2_{2}-\mathrm{F} 1\right) 2 /\left\{4\left[\sigma_{\mathrm{BC} 2}^{2}-0 / 5\left(\sigma_{\mathrm{F} 1}^{2}+\sigma_{\mathrm{P} 2}^{2}\right)\right]\right.
\end{aligned}
$$

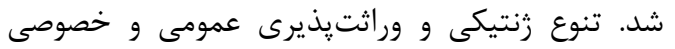

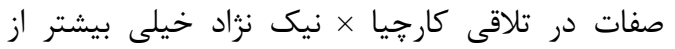

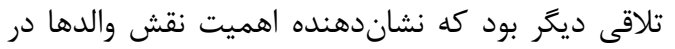

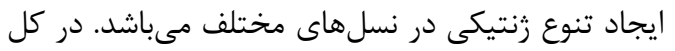

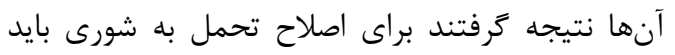

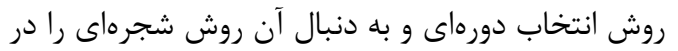

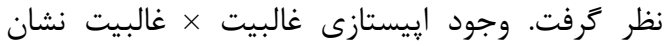

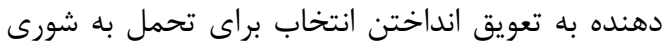
تا جند نسل مى بـاشد تا اين اثرات تثبيت شوند.
يزوهشنامه اصلاح گياهان زراعى/ سال هشتم/ شماره VV/ بهار ه9 II .

صحت مدل افزايشى- غالبيت با استفاده از معادلات زير تست مىشود ( • (Y): $\mathrm{C}=4, \mathrm{~B}=2 \mathrm{BC}_{2}-\mathrm{P}_{2}-\mathrm{F}_{1}, \mathrm{~A}=2 \mathrm{BC}_{1}-\mathrm{P}_{1}-\mathrm{F}_{1}$ . $F_{2}-2 F_{1}-P_{1}-P_{2}$
تجزيه ميانغين نسل ها تحت تنش شورى

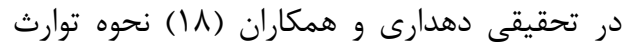

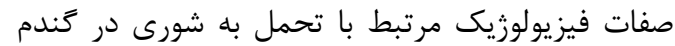

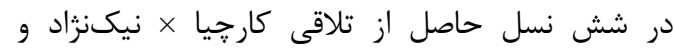

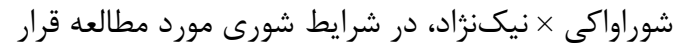

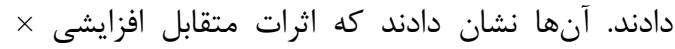

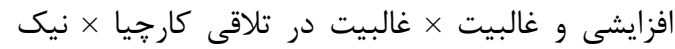

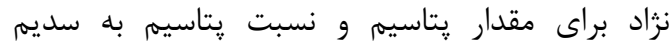

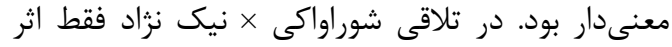

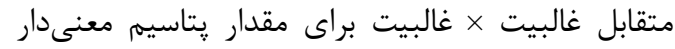


به تمامى تركيبات ممكنه بين n لاين، تلاقى داى آلل

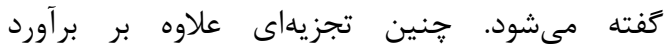

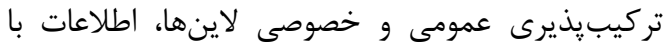

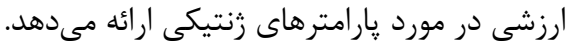

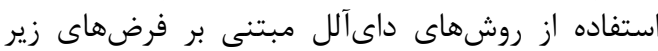

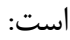
1- والدين و لاينها بايد خالص و هموزيگوت باشند (در روش گريفينَ الزامى نيست.).

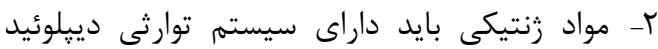

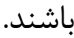

ץ- عدم وجود اثرات مادرى يا سيتويلاسمى

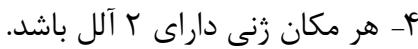

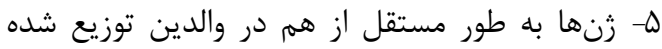
باشند. - مان 9ـ اثر إيستازى وجود نداشته باشد.

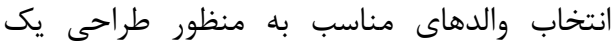

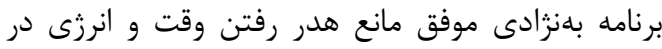

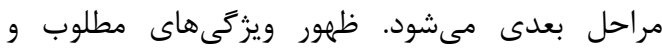

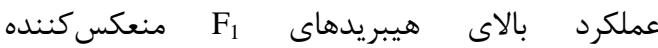

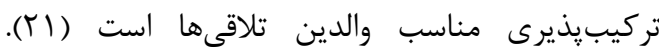

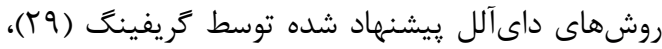

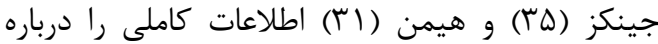

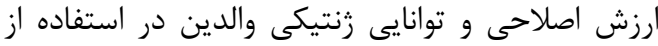

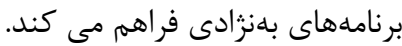
روش هاى مختلف تلاقى دى دي آلل

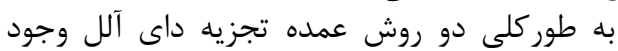

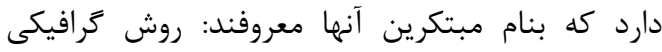

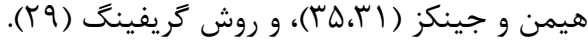
r-I- روش هيمن و جينكز (اس، (r)

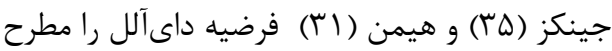

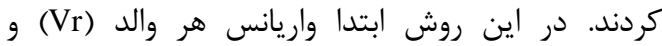

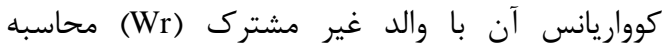

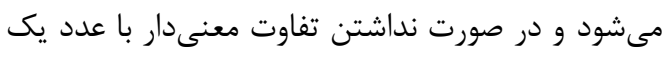

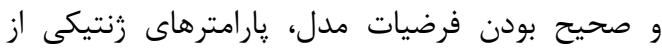

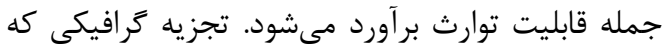

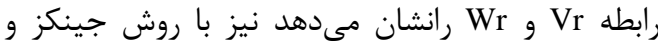

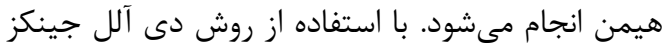

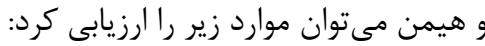

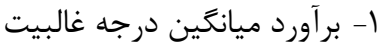
r- بررسى وجود و تعيين اثرات إيستازى دئي

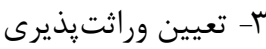

ץ كار

كاربرد تجزيه داى آلل در در اصلاحنباتات به به منظور غربال كردن بهترين تركيب شوندهها و استفاده از مسئله

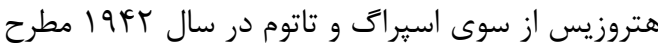

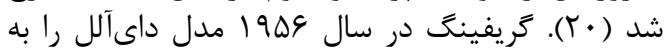

دشتى و همكاران (9) وراثت تحمل به شورى در

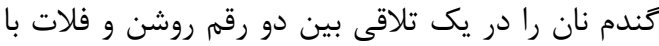

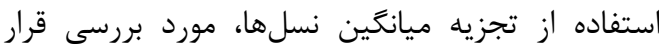

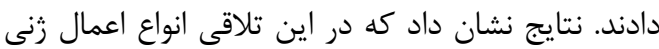

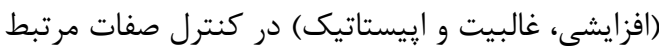

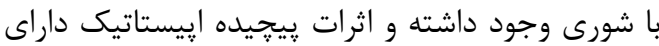
اهميت زيادى هستند. نسبت

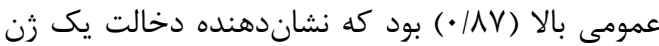

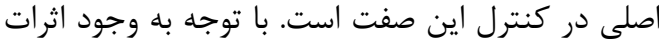

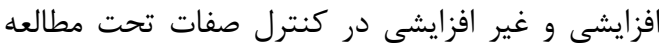

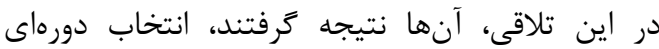

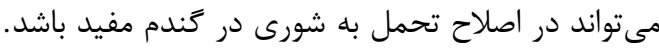

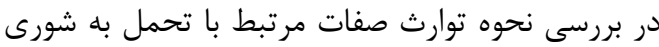

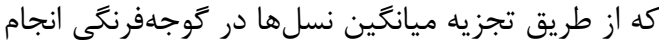

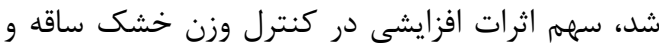

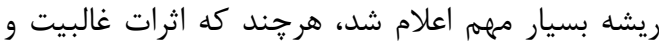

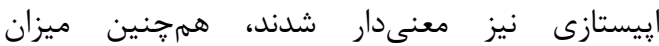

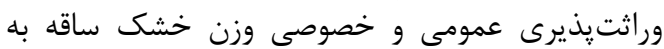

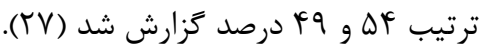

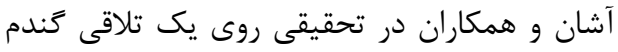

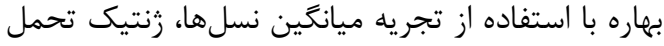

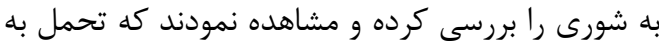
شورى تحت تأثير اثر افزايشى زنى زنها

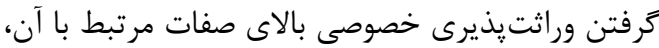

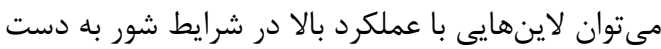

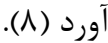

در تحقيقى روى برنج با استفاده از تجزيه ميانگين

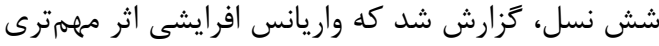

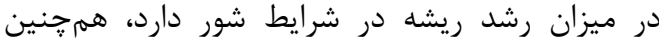

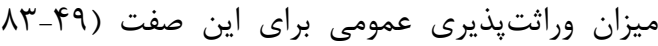

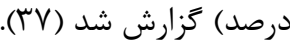

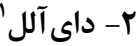
طرحهاى تلاقى داى آلل يك ابزار مهرم در برنامههاى

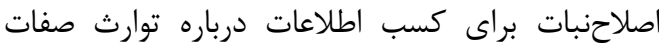

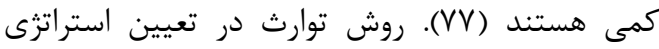

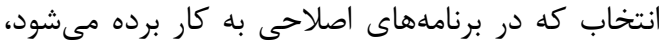

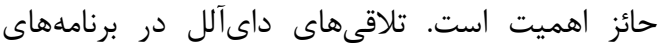

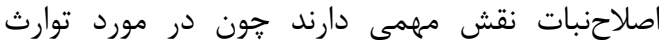

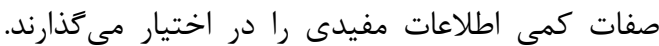

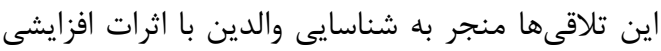

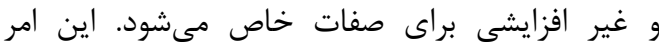

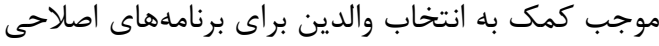

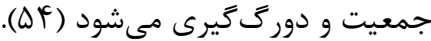

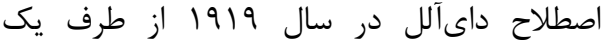
متخصص اصلاح دام به نام اسميت براى طرح فاد فاكتوريل

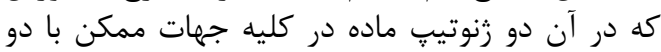

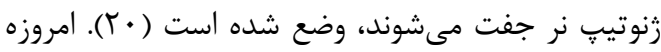


در تجزيه داى آلل سه كروه از مواد به نامهاى

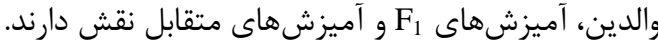

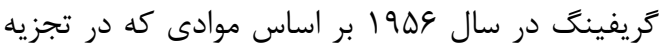

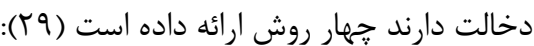

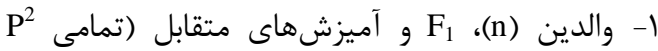
تركيب ممكنه)

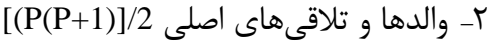

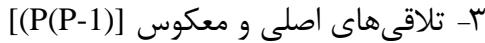

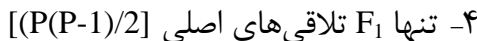

منظور بررسى عمل زنهاى كنترلكننده يك صفت

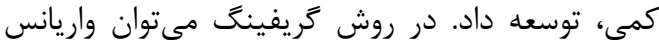

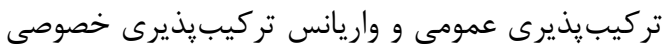

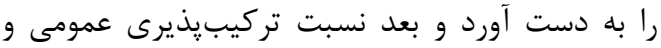

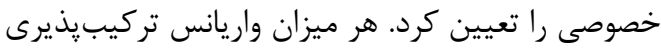

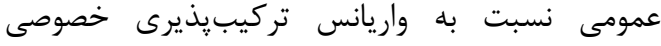

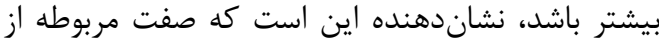

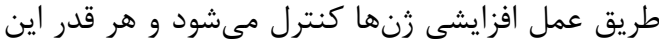

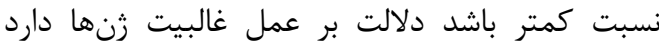

.$(Y \cdot)$

\begin{tabular}{|c|c|c|c|}
\hline \multicolumn{4}{|c|}{ جدول ا- تجزيه واريانس تلاقى داى آلل (روش اول كريفينگ- مدل ك) } \\
\hline منابع تغييرات & درجه آزادى & ميانكَين مربعات & اميد رياضى اجزاى واريانس \\
\hline تركيبذيذيرى عمومى (GCA) & $(\mathrm{p}-1)$ & MSgca & $\sigma_{\mathrm{e}}^{2}+\left[2(\mathrm{p}-1)^{2} / \mathrm{p}\right] \sigma_{\text {sca }}^{2}+2 \mathrm{p} \sigma^{2}{ }_{\mathrm{gcc}}$ \\
\hline تركيبذيذيرى خصوصى (SCA) & $\mathrm{P}(\mathrm{P}-1) / 2$ & MSsca & $\sigma_{e}^{2}+\left[2\left(p^{2}-p+1\right) / p^{2}\right] \cdot \sigma_{s c a}^{2}$ \\
\hline اثرات متقابل (Reciprocal) & $\mathrm{P}(\mathrm{p}-1) / 2$ & MS r & $\sigma_{\mathrm{e}}^{2}+2 \sigma_{\mathrm{r}}^{2}$ \\
\hline خطا & $\mathrm{m}$ & $\mathrm{Me}^{\prime}$ & $\sigma^{2} \mathrm{e}$ \\
\hline
\end{tabular}

جدول r- تجزيه واريانس تلاقى داى آلل (روش دوم گريفينگ- مدل r)

\begin{tabular}{|c|c|c|c|}
\hline منابع تغييرات & درجه آزادى & ميانگين مربعات & اميد رياضى اجزاى واريانس \\
\hline تركيب پيذيرى عمومى (GCA) & $(\mathrm{p}-1)$ & MSgca & $\sigma_{\mathrm{e}}^{2}+\sigma_{\mathrm{sca}}^{2}+(\mathrm{P}+2) \sigma_{\mathrm{gca}}^{2}$ \\
\hline تركيبذيذيرى خصوصى (SCA) & $\mathrm{P}(\mathrm{p}-1) / 2$ & MSsca & $\sigma^{2}{ }_{e}+\sigma_{\text {sca }}^{2}$ \\
\hline خطا & M & $\mathrm{Me}^{\prime}$ & $\sigma^{2} \mathrm{e}$ \\
\hline
\end{tabular}

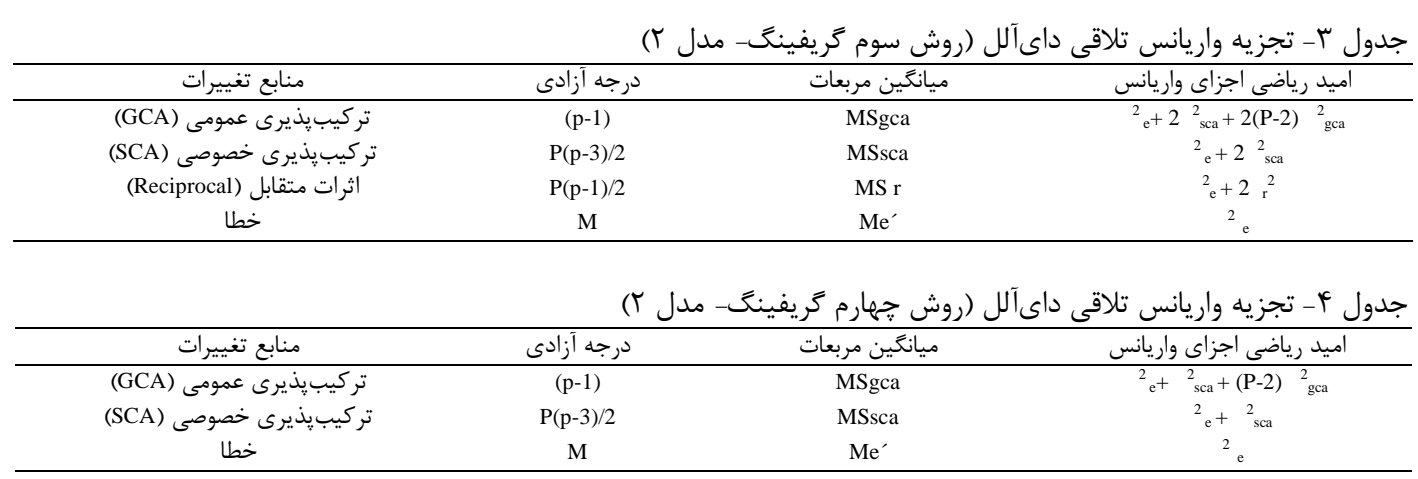

تحقيق ديخرى در گياه برنج با استفاده از تلاقى

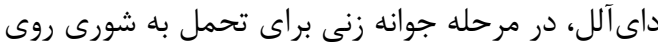

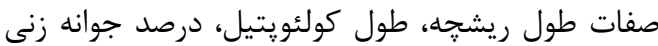

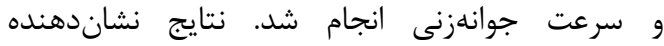

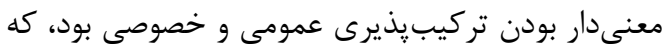

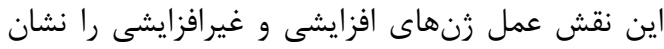

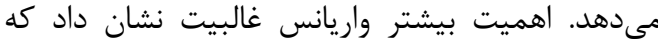

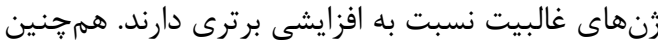

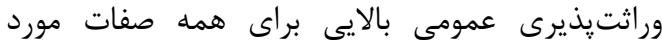

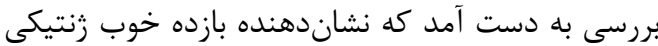

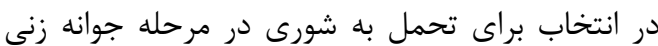

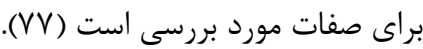

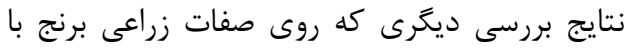

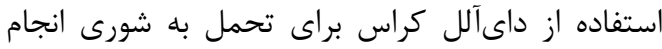

\section{تلاقى هاى داى آلل تحت تنش شورى}

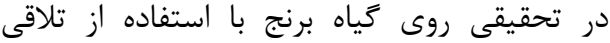

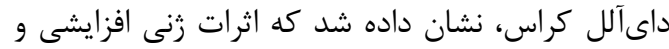

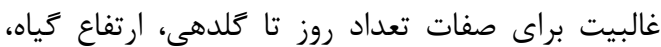

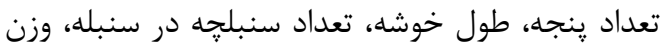

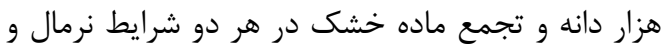

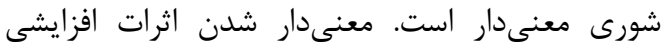

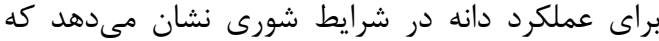

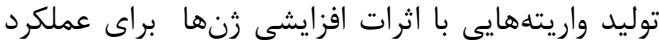

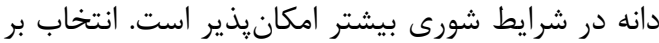

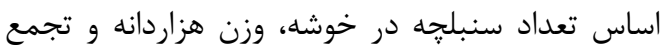

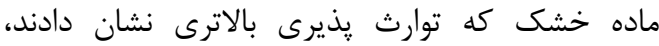

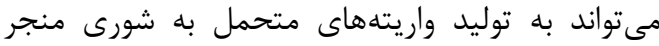

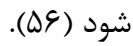


شورى در لوبياى سودانى از طريق انتخاب تودهاى و اصلاح امكانيذير است.

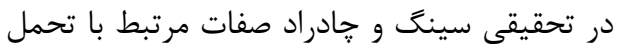

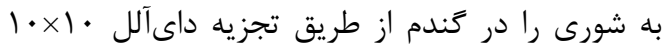

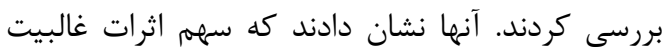

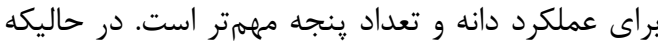

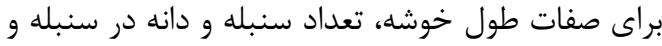

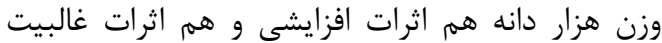

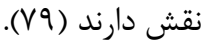

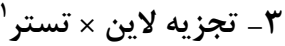

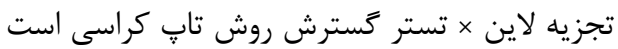

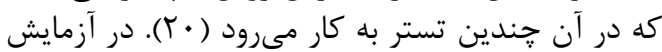

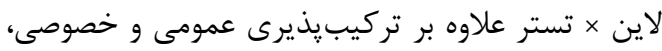

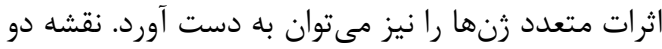

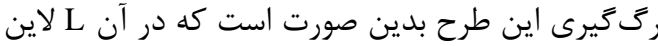

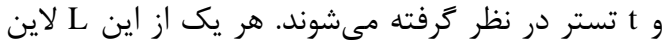

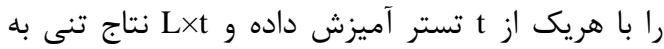

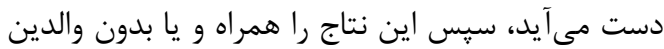

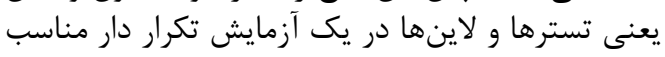

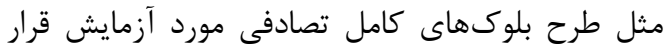

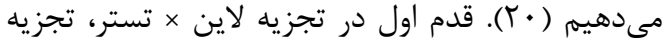

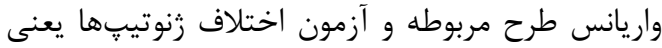

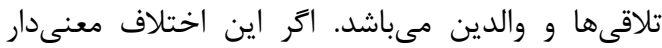

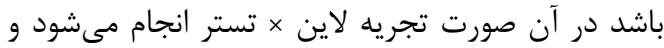

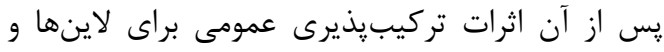

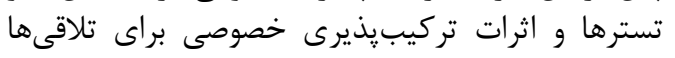

$$
\text { محاسبه مىشود. }
$$

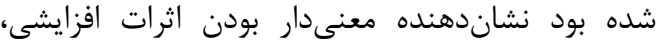

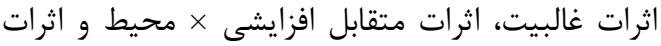

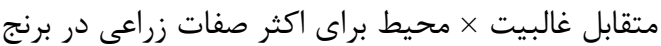

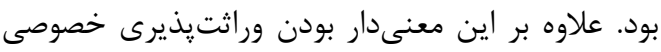

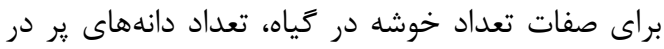

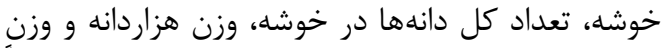

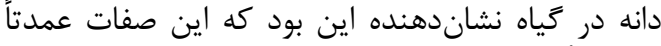

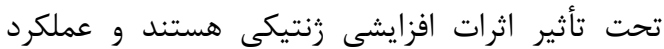

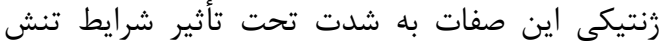

شورى واقع شده است ( • (9).

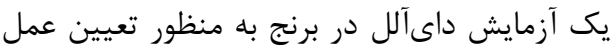

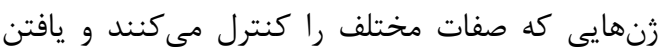

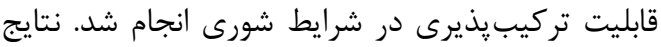

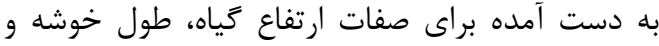

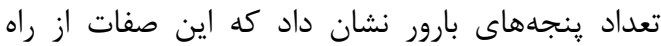

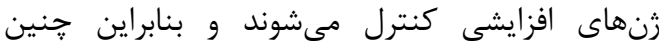

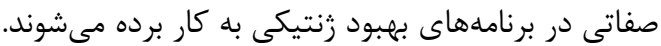

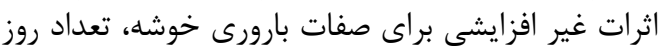
تا رسيدن، وزن خشرات خشى ساقه، مقدار

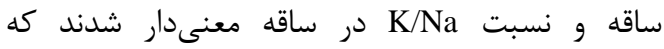

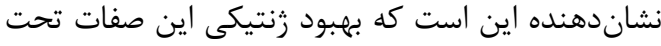

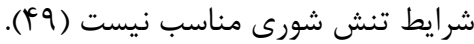

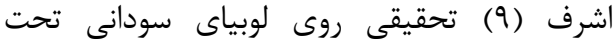

شرايط تنش شورى با استفاده از تجزيه دائ آلل انجام

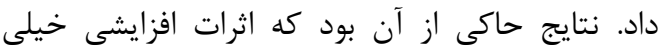

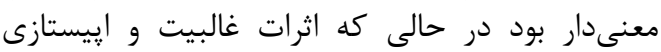

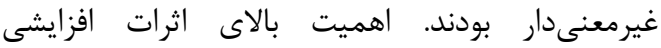
نشاندهنده اين است كه بهبود قابل توجه تحمل بهل به جدول ه- تجزيه واريانس تجزيه لاين×تستر (مدل ثابت)

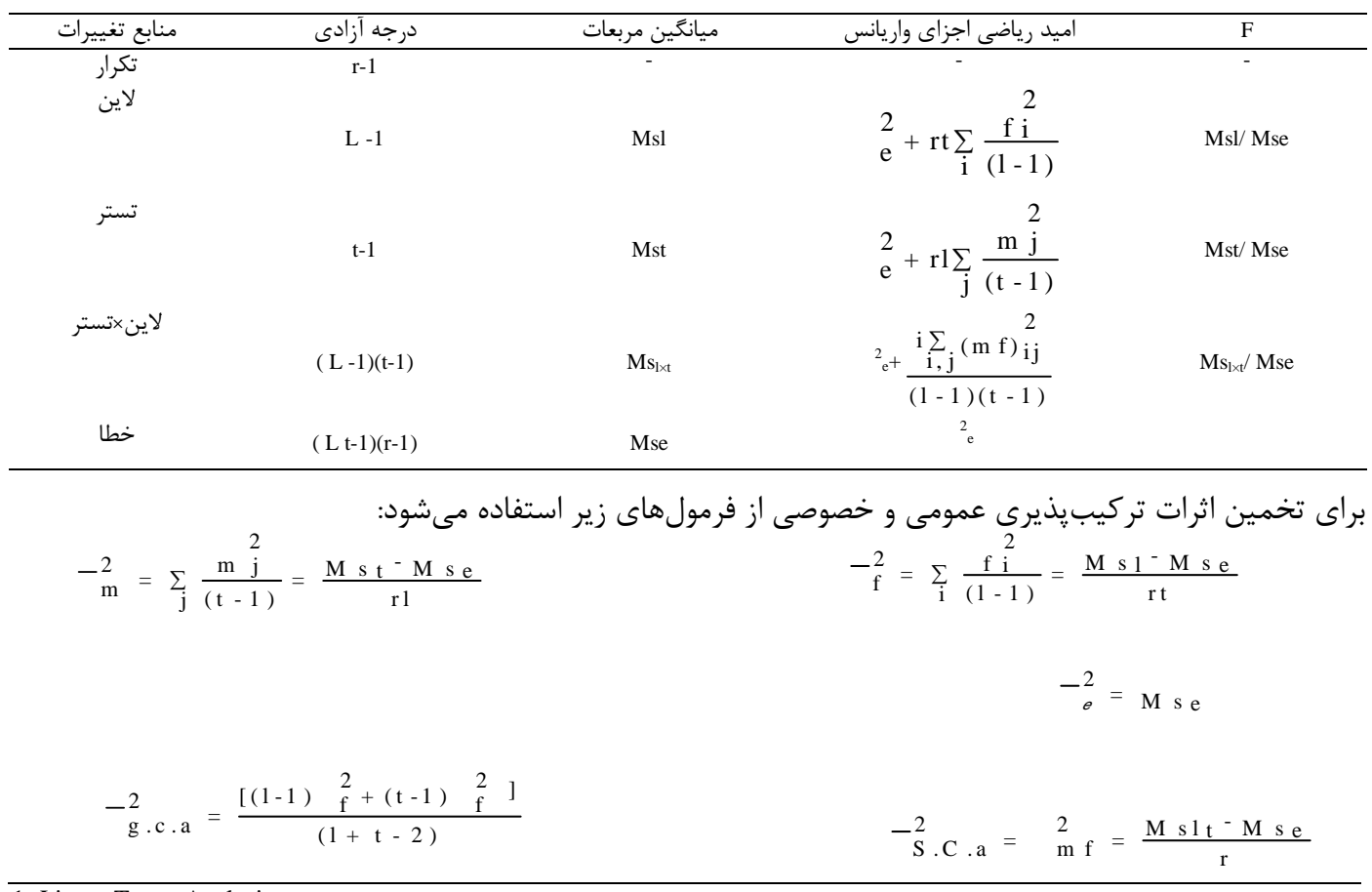


r)

ديا سانكار و همكاران (IV)، از (IV)

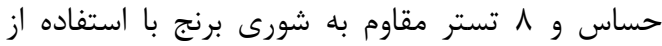

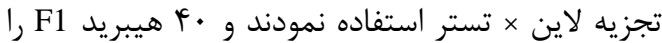

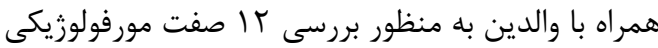

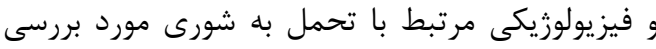

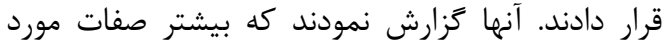

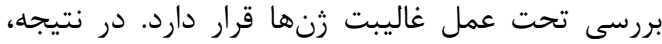

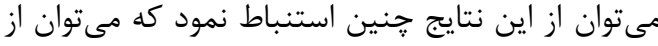

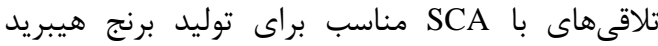
مقاوم به شورى سود برى بان

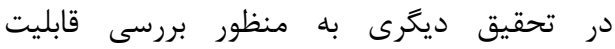

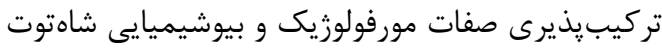
تحت شرايط تنش شورى از تجزيه لاين ×

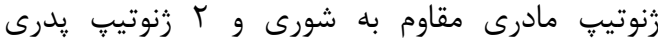

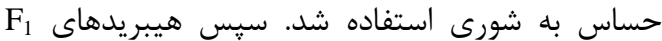

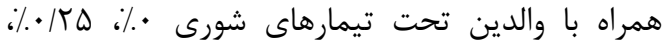

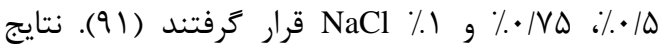

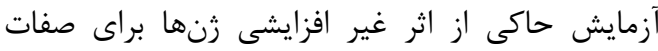

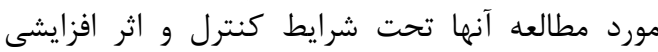

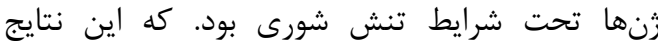

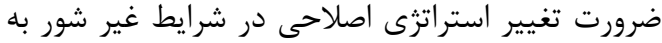
شور را مىرساند.

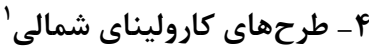

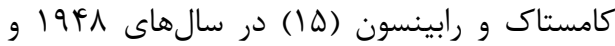

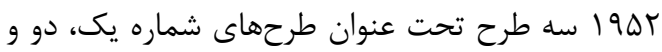

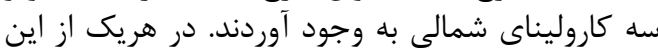

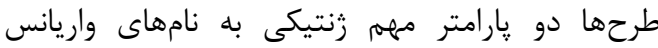

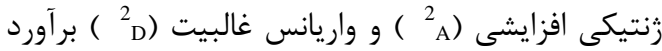

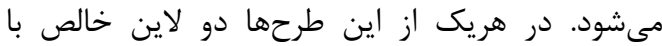

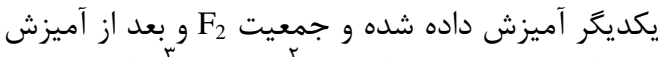

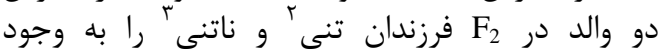

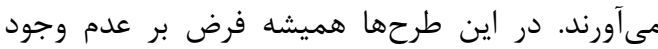

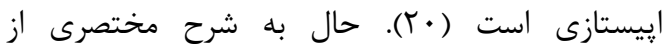

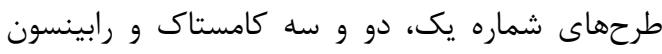

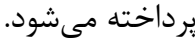

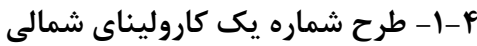

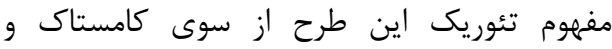

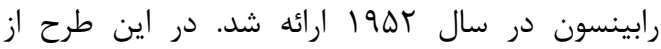

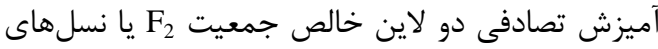

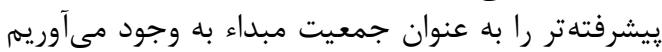

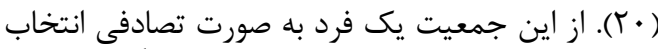

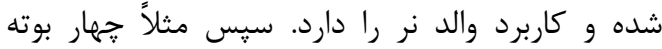

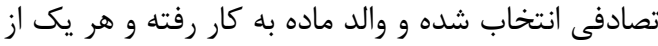

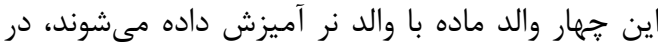

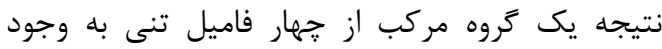

يزوهشنامه اصلاح گياهان زراعى/ سال هشتم/ شماره / / بهار ه9r I كه در اين فرمولها واريانس نر،

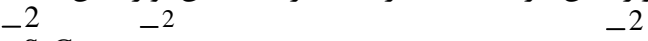

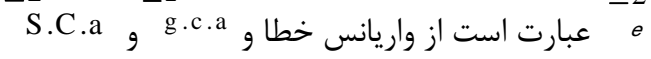

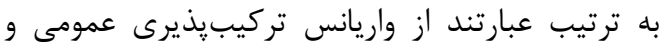
خصوصى. تجزيه لاين × تستر و تنش شورى:

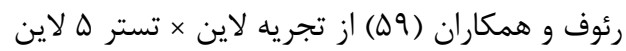
B

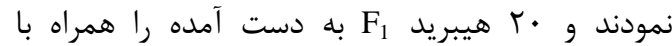

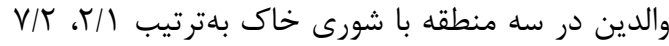

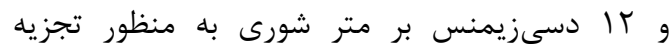
واريانس فنوتييى صفات مورفولوزيكى ارتئي ارتفاع بوته، تعداد

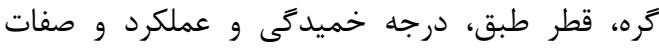

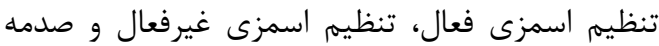

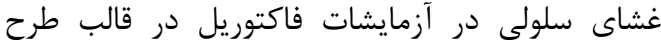

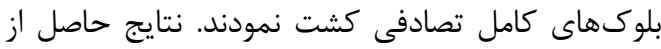

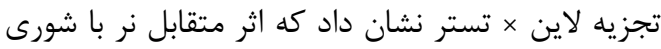

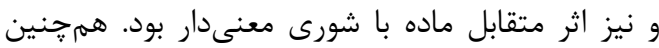

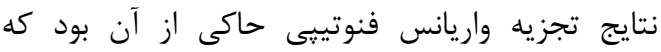

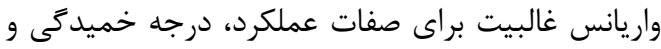

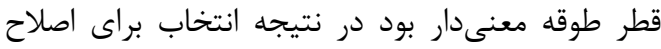

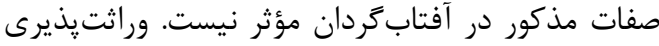

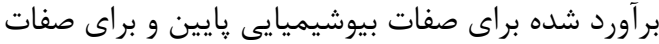

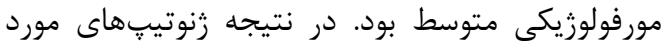

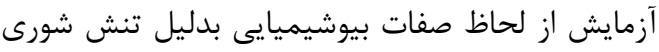

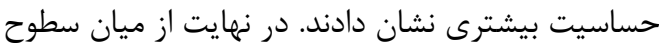

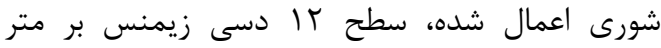

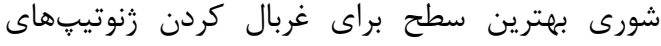

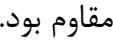

سعيد و همكاران (VT) در آزمايشى به منظور يافتن

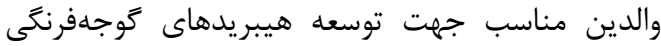

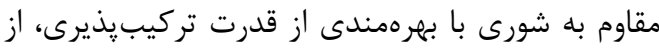
تجزيه لاين × تستر استفاده نمودند و و

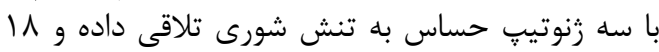

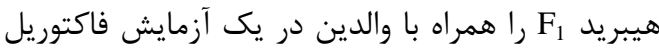

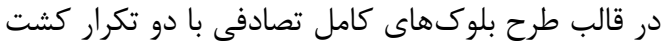

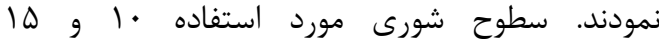

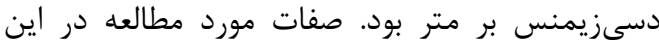

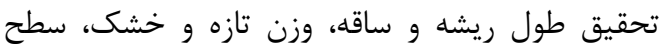

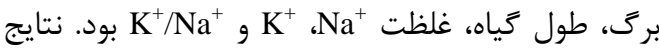

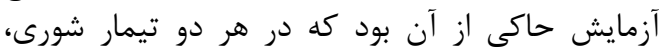

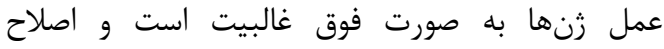

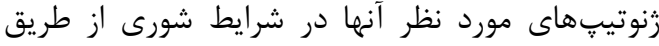
توليد واريتههاى هيبريد امكانيذير است. 
در داخل نرها آشيانه گرفتهاند. در هر صورت، هر گر كروه

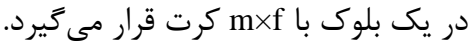

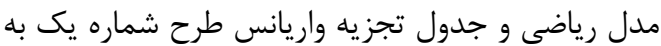

$\mathrm{Xijk}=\mu+\mathrm{r}_{\mathrm{k}}+\mathrm{m}_{\mathrm{i}}+\mathrm{f}_{\mathrm{j} / \mathrm{i}}+\mathrm{e}_{\mathrm{ijk}}$

$$
\text { شرح زير مىباشد: }
$$

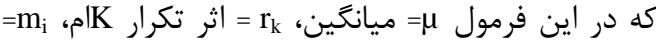

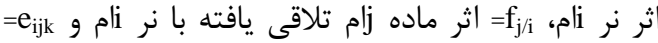
اشتباه آزمايشى مى ناشند.
مى آيد كه والد نر در نظر گرفته ميىشوند و بـ به همين

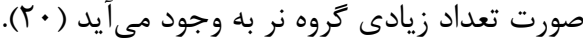

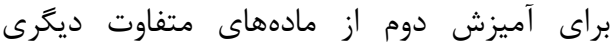

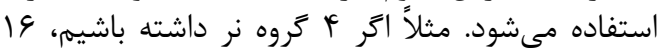

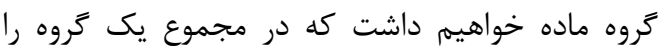

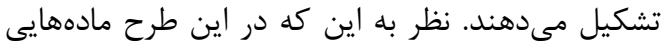

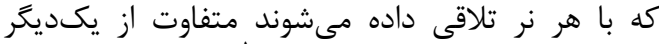
هستند آن را طبقهبندى آشيانهاى ' تويند يعنى مادئ مادهها

\begin{tabular}{|c|c|c|c|c|}
\hline \multirow{2}{*}{ منابع تغييرات } & \multirow{2}{*}{ درجه آزادى } & \multirow{2}{*}{ ميانگين مربعات } & \multicolumn{2}{|c|}{ اميد رياضى } \\
\hline & & & اجزاى واريانس & كوواريانس خويشاوندان \\
\hline تكرار (r) & $\mathrm{r}-1$ & - & - & - \\
\hline نر (m) & $\mathrm{m}-1$ & $\mathrm{Ms}_{\mathrm{m}}$ & $\sigma^{2}{ }_{e}+r \sigma^{2}{ }_{f / m}+r f \sigma_{m}^{2}$ & $\begin{array}{c}{ }^{2}{ }_{\mathrm{e}}+\mathrm{r}\left(\mathrm{COV}_{\mathrm{FS}}-\mathrm{COV}_{\mathrm{HS}}\right)+\mathrm{rf} \\
\sigma\left(\mathrm{COV}_{\mathrm{HS}}\right)\end{array}$ \\
\hline ماده در نر (f/m) & $m(f-1)$ & $\mathrm{Ms}_{\mathrm{f} / \mathrm{m}}$ & $\sigma_{e}^{2}+r \sigma_{f / m}^{2}$ & $\sigma_{\mathrm{e}}^{2}+\mathrm{r}\left(\mathrm{COV}_{\mathrm{FS}}-\mathrm{COV}_{\mathrm{HS}}\right)$ \\
\hline خطا (e) & $(\mathrm{r}-1)(\mathrm{mf}-1)$ & Mse & $\sigma_{\mathrm{e}}^{2}$ & $\sigma_{\mathrm{e}}^{2}$ \\
\hline 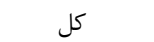 & $\mathrm{rmf}-1$ & - & - & - \\
\hline
\end{tabular}

خويشاوندان موجود در آن تلاقى است و به طور غير

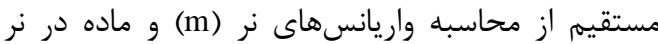

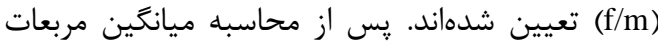

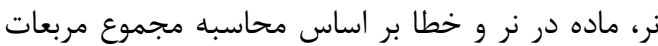

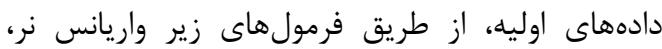

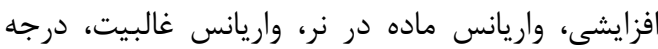

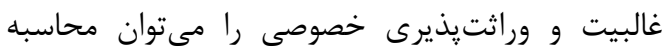
نمود.

$$
\begin{aligned}
& \overline{\mathrm{d}}=\sqrt{\frac{2\left(\begin{array}{c}
2 \\
\left.\sigma_{\mathrm{f} \backslash \mathrm{m}^{-}{ }^{2} \mathrm{~m}}\right) \\
2 \\
\sigma_{\mathrm{m}}
\end{array}\right.}{2}} \\
& \mathrm{hn}=\frac{{ }^{2} \sigma \mathrm{m}}{2} \frac{2}{\frac{\sigma \mathrm{e}}{\mathrm{r}}+4 \underset{\sigma \mathrm{f} \backslash \mathrm{m}}{2}}
\end{aligned}
$$

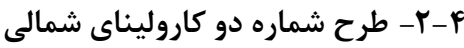

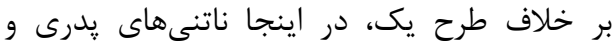

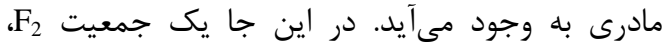

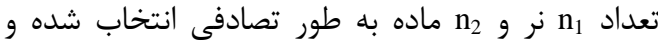

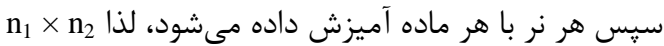

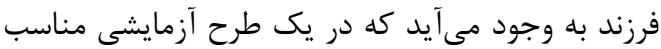

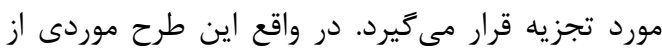

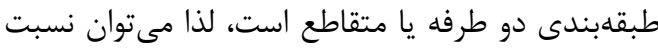

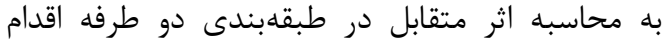

$$
\text { نمود. }
$$

در اين طرح نيز هدف محاسبه واريانس زنتيكى

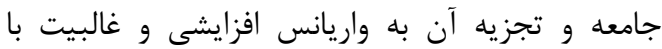

يكى از قديمىترين مشاهدات برجسته زنتيك آن است

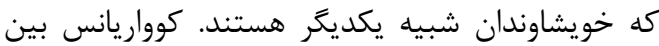

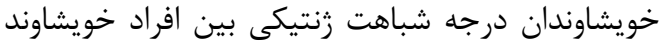

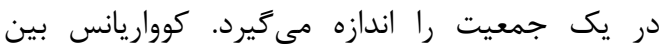

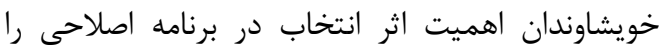

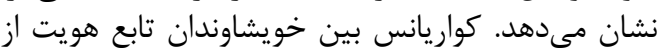

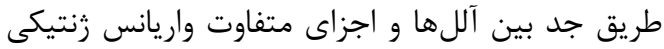

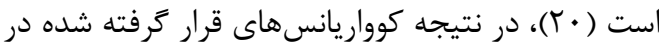

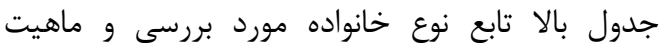

$$
\begin{aligned}
& \underset{\sigma \mathrm{m}}{2}=\frac{\mathrm{ms} \mathrm{m}^{-} \mathrm{msf} \backslash \mathrm{m}}{\mathrm{rf}}=\mathrm{CovHS}=\frac{1}{4} \sigma_{\mathrm{a}}^{2} \\
& \underset{\sigma \mathrm{f} \backslash \mathrm{m}}{2}=\frac{\mathrm{msf} \backslash \mathrm{m}^{-} \mathrm{mse}}{\mathrm{r}}=\frac{1}{4} \sigma_{\mathrm{a}}^{2}+\frac{1}{4} \sigma \mathrm{d} \\
& \sigma_{\mathrm{a}}^{2}=4_{\sigma \mathrm{m}}^{2} \\
& \underset{\sigma d}{2}=\underset{\sigma f \backslash m}{2}-4 \underset{\sigma m}{2}
\end{aligned}
$$

كه در اين فرمولها $-2$

عبارتست از واريانس ماده در نر، $\begin{gathered}2 \\ \text { of \اm }\end{gathered}$

ازي واريانس خطا، مa a ع عبارتست از واريانس افزايشى، تمبارتست از واريانس غالبيت،

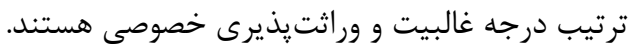
طرح شماره يك بيشتر از طرحهاى ديخر (بجزء دى دى آلل)

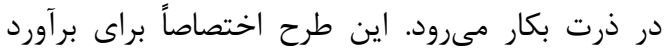

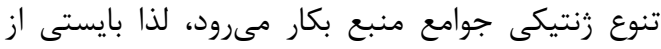

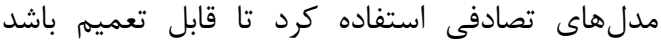
. (

1- Nested Design 
r

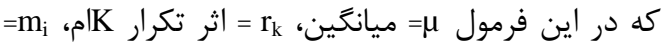

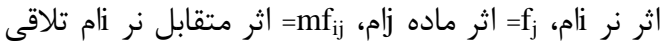

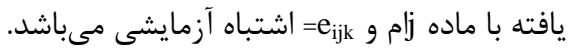

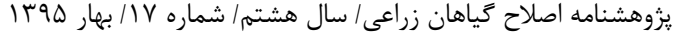

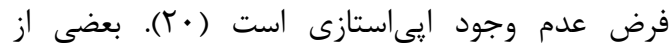
محققين اين طرح را طرح دى آلل و نيز طرح فاكتوريل كويند. مدل رياضى طرح شماره دو به شرح زير مىباشد: $X i j k=\mu+r_{k}+m_{i}+f_{j}+m f_{i j}+e_{i j k}$

جدول V- تجزيه واريانس طرح شماره دو كاروليناى شمالى

\begin{tabular}{|c|c|c|c|c|}
\hline \multirow{2}{*}{ منابع تغييرات } & \multirow{2}{*}{ درجه آزادى } & \multirow{2}{*}{ ميانكَين مربعات } & \multicolumn{2}{|c|}{ اميد رياضى } \\
\hline & & & اجزاى واريانس & اجزاى كوواريانس خويشاوندان \\
\hline تكرار (r) & $\mathrm{r}-1$ & - & - & - \\
\hline نر (m) & $\mathrm{m}-1$ & $\mathrm{Ms}_{\mathrm{m}}$ & $\sigma_{\mathrm{e}}^{2}+\mathrm{r} \sigma_{\mathrm{f} \times \mathrm{m}}^{2}+\mathrm{rf} \sigma_{\mathrm{m}}^{2}$ & $\begin{array}{c}{ }_{\mathrm{e}}^{2}+\mathrm{r}\left(\mathrm{COV}_{\mathrm{FS}}-\mathrm{COV}_{\mathrm{HSm}}-\mathrm{COV}_{\mathrm{HSf}}\right)+\mathrm{rf} \\
\sigma\left(\mathrm{COV}_{\mathrm{HSm}}\right)\end{array}$ \\
\hline ماده (f) ماد) & $f-1$ & $\mathrm{Ms}_{\mathrm{f}}$ & $\sigma_{\mathrm{e}}^{2}+\mathrm{r} \sigma_{\mathrm{f} \times \mathrm{m}}^{2}+\mathrm{rm} \sigma_{\mathrm{f}}^{2}$ & $\begin{array}{c}{ }_{\mathrm{e}}^{2}+\mathrm{r}\left(\mathrm{COV}_{\mathrm{FS}}-\mathrm{COV}_{\mathrm{HSm}-} \mathrm{COV}_{\mathrm{HSf}}\right)+\mathrm{rm}( \\
\left.\sigma \mathrm{COV}_{\mathrm{HSf}}\right)\end{array}$ \\
\hline ماده × نر (f×m) & $(\mathrm{m}-1)(\mathrm{f}-1)$ & $\mathrm{Ms}_{\mathrm{f} \times \mathrm{m}}$ & $\sigma_{\mathrm{e}}^{2}+\mathrm{r} \sigma_{\mathrm{f} \times \mathrm{m}}^{2}$ & $\sigma_{\mathrm{e}}^{2}+\mathrm{r}\left(\mathrm{COV}_{\mathrm{FS}}-\mathrm{COV}_{\mathrm{HSm}}-\mathrm{COV}_{\mathrm{HSf}}\right)$ \\
\hline خطا (e) & $(\mathrm{r}-1)(\mathrm{mf}-1)$ & Mse & $\sigma_{e}^{2}$ & $\sigma_{\mathrm{e}}^{2}$ \\
\hline كل & $\mathrm{rmf}-1$ & - & - & - \\
\hline
\end{tabular}

واريانس نر × ماده ، واريانس غالبيت، درجه غالبيت و وراثتيذيرى خصوصى را مى توان محاسبه نمود.

$$
\begin{aligned}
& \overline{\mathrm{d}}=\sqrt{\frac{2 \sigma \mathrm{mf}}{2}} \\
& \mathrm{hn}
\end{aligned}
$$

صورت تصادفى از نسل F انتخاب شده و هر بوته

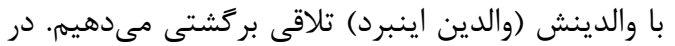

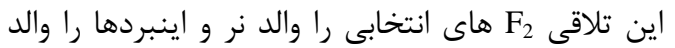

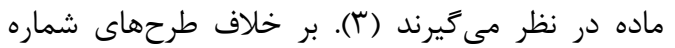

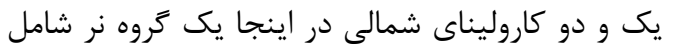

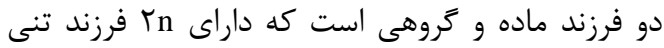

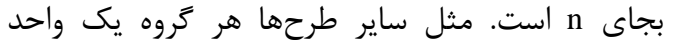

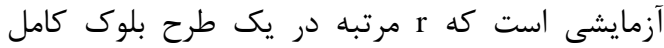

$$
\text { تصادفى تكرار مىشود ( • (؟). }
$$

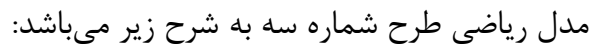
$X i j k=\mu+r_{k}+m_{i}+f_{j}+m p_{i j}+e_{i j k}$

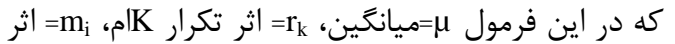

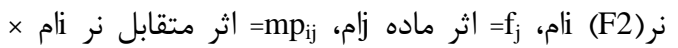

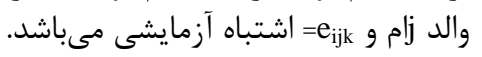

קس از محاسبه ميانگين مربعات نر، ماده، ماده × نر و

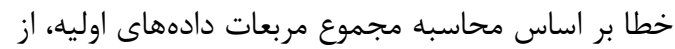
طريق فرمولهاى زير واريانس نر، مجاد ماده، افزايشى، دادهاى اوليه، $\underset{\sigma \mathrm{m}}{2}=\underset{\sigma \mathrm{f}}{2}=\frac{\mathrm{msm}^{-} \mathrm{msf}^{*} \mathrm{~m}}{\mathrm{rf}}=\operatorname{CovHS}=\frac{1}{4}{ }^{2} \mathrm{a}$ $\underset{\sigma \mathrm{mf}}{2}=\frac{\mathrm{msf}^{-} \mathrm{msf}^{*} \mathrm{~m}}{\mathrm{rm}}=\frac{1}{4} \sigma \stackrel{2}{\sigma \mathrm{d}}$ $\underset{\sigma \mathrm{a}}{2}=4_{\sigma \mathrm{m}}^{2}=4_{\sigma \mathrm{f}}^{2}$ $\sigma \mathrm{d}=4 \sigma \mathrm{mp}$

كه در اين فرمولها 2 ز ع عبارتست Off 2 واريانس نر × ماده، مa

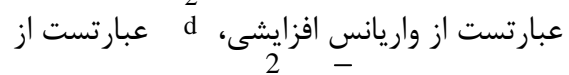
واريانس غالبيت، و و و وراثتيذيرى خصوصى هستند.

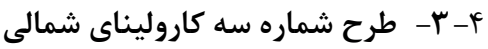

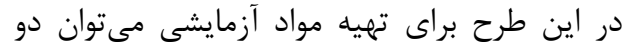

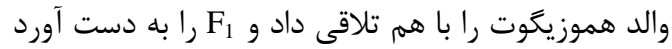

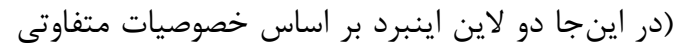

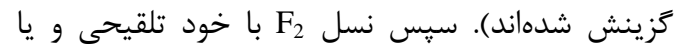

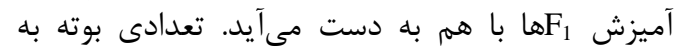




\begin{tabular}{|c|c|c|c|}
\hline منابع تغييرات & درجه آزادى & ميانگين مربعات & اميد رياضى اجزاى واريانس \\
\hline تكرار (r) & $\mathrm{r}-1$ & & \\
\hline والد (p) & $\mathrm{m}-1$ & Msp & $\sigma_{\mathrm{e}}^{2}+2 r \sigma_{\mathrm{m}}^{2}$ \\
\hline نر & $f-1$ & Msm & $\sigma_{\mathrm{e}}^{2}+r \sigma_{\mathrm{f} \times \mathrm{m}}^{2}+\mathrm{rm} \sigma_{\mathrm{f}}^{2}$ \\
\hline والد × نر (p×m) & $(\mathrm{m}-1)(\mathrm{f}-1)$ & $\mathrm{Ms}_{\mathrm{p} \times \mathrm{m}}$ & $\sigma_{e}^{2}+r \sigma_{p \times m}^{2}$ \\
\hline خطا (e) & $(\mathrm{r}-1)(\mathrm{mf}-1)$ & Mse & $\sigma_{\mathrm{e}}^{2}$ \\
\hline كل & $\mathrm{rmf}-1$ & & \\
\hline
\end{tabular}

والد، واريانس غالبيت، درجه غالبيت و وراثتيذيرى خصوصى را مىتوان محاسبه نمود.

$\underset{\sigma \mathrm{m}}{2}=\frac{\mathrm{msm}^{-} \mathrm{mse}}{2 \mathrm{r}}=\frac{1}{4} \underset{\sigma \mathrm{a}}{2}$

$\underset{\sigma \mathrm{mp}}{2}=\frac{\mathrm{msmp}^{-} \mathrm{mse}}{\mathrm{r}}=\stackrel{2}{\sigma \mathrm{d}}$

$\underset{\sigma d}{2}=\stackrel{2}{\sigma m p}$

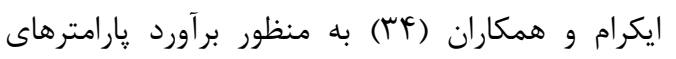

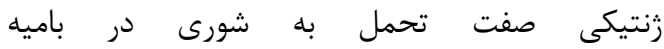
از طرح شماره دو دو دارئ (Abelmoschus esculentus L.)

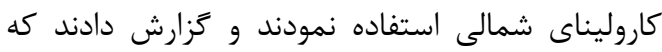
4.

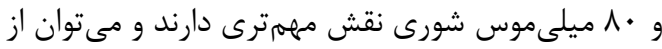

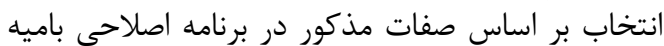

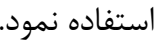

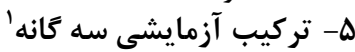

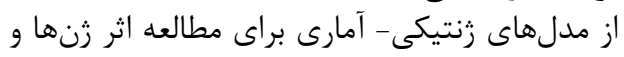

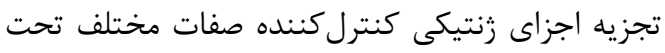

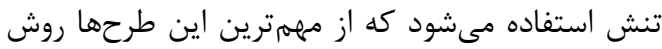

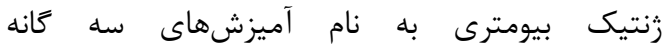

(Triple Test Cross)

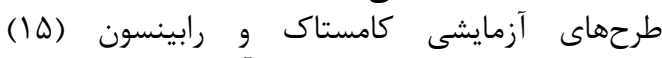

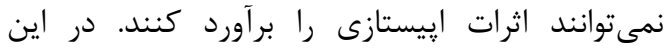

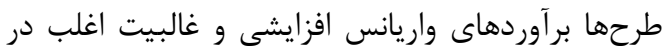

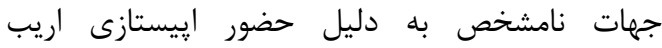

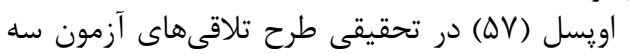

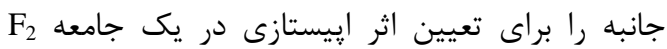

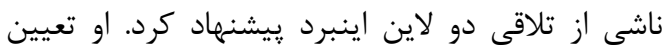

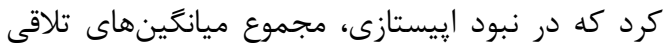

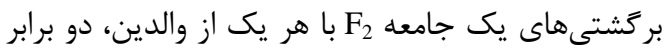

يس از محاسبه ميانگين مربعات نر، والد در نر و خطا

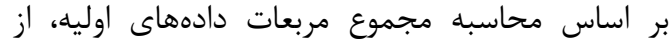

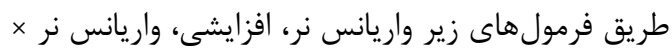

$$
\underset{\sigma \mathrm{a}}{2}=\frac{1}{4} 4 \underset{\sigma \mathrm{m}}{2}
$$$$
\overline{\mathrm{d}}=\sqrt{\frac{\sigma_{\mathrm{mp}}}{2}}
$$

$$
\mathrm{hn}=\frac{4_{\sigma \mathrm{m}}^{2}}{\frac{\sigma \mathrm{e}}{\mathrm{r}}+4_{\sigma \mathrm{m}}^{2}+\stackrel{2}{\sigma \mathrm{mp}}}
$$

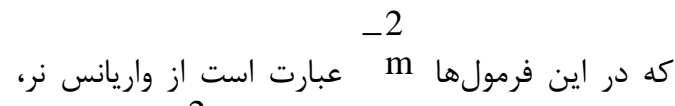
2

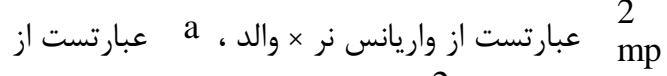
واريانس افزايشى، 2 مd عبارتست از واريانس غالبيت، نيز به ترتيب درجه غالبيت و وراثتيذيرى hn و خصوصى هستند. طرحهاى كاروليناى شمالى و مقاومت به شورى:

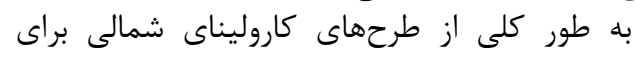

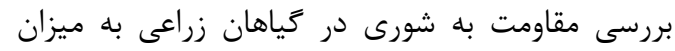

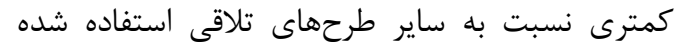

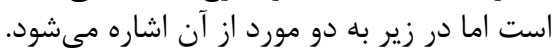

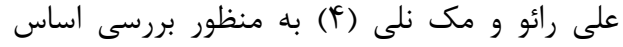

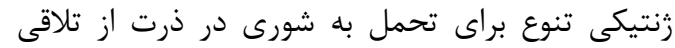

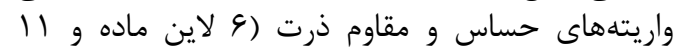

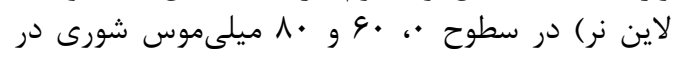

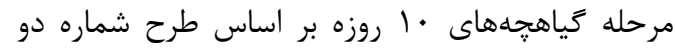

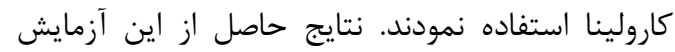

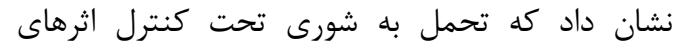

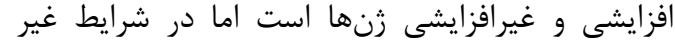

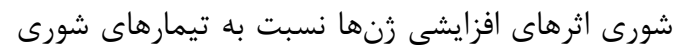


وجود آثار إيستازى نشان مىدهد كه توارث صفات

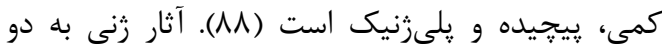

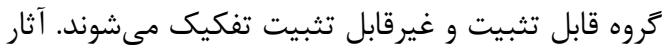

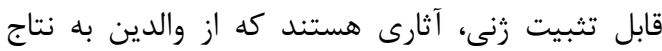

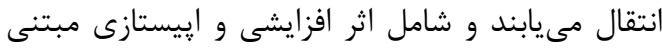

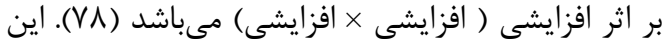

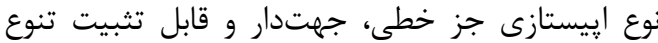

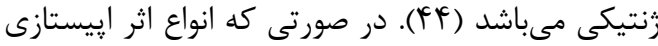

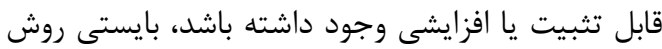

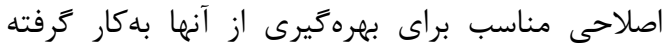

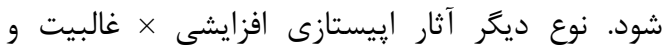

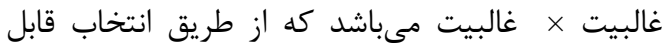
تثبيت نيستند و امكان دارد براى توليد هيبريد مناسب البيت

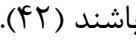
آزمون إييستازى و تخمين اثرات افزايشى و غالبيت:

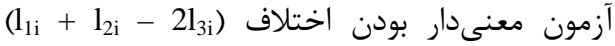

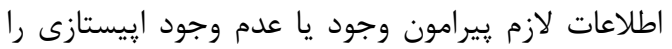

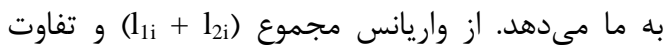

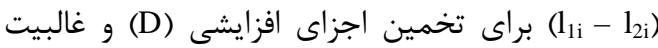

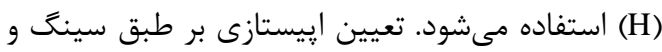

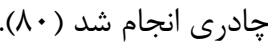
$\left(1_{1 i}+1_{2 i}-21_{3 i}\right) \quad(I=$ آزمون معنى genotypes) مىباشد. بنابراين مقدار محين كرد

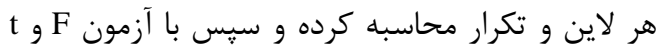

$\mathrm{P}_{1} \times \mathrm{F}_{2}=\mathrm{L}_{1} \quad \mathrm{P}_{2} \times \mathrm{F}_{2}=\mathrm{L}_{2} \quad \mathrm{~F}_{1} \times \mathrm{F}_{2}=\mathrm{L}_{3}$ إِيستازى كل به دو بخش تقسيم مى شىود:

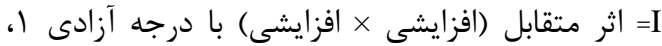

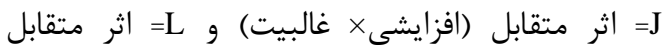

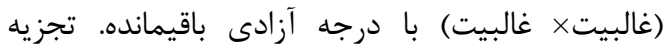

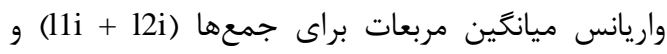

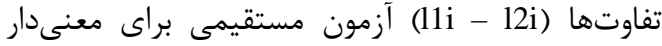
بودن اثرات افزايشى و غالبيت فراهم مى كند.
ميانگين تلاقىهاى بر گشتى آن با نسل F1 است.

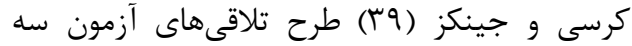

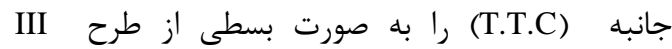

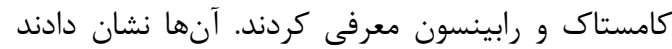

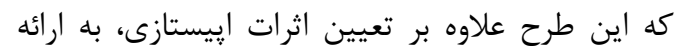

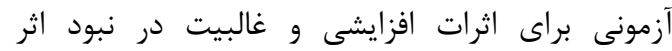
إيستازى قادر مىباشد.

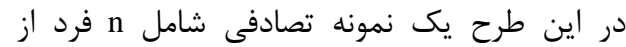

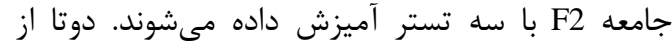

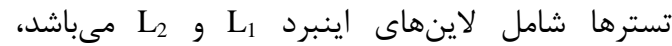

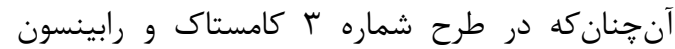

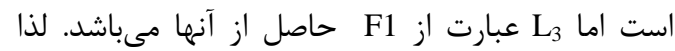

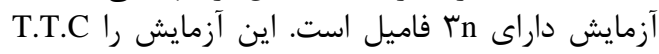
كويند.

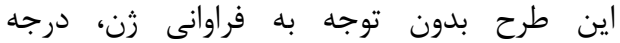

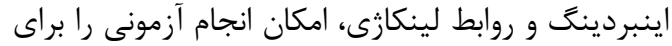

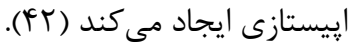

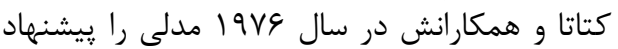

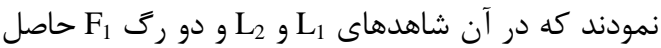

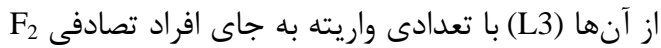

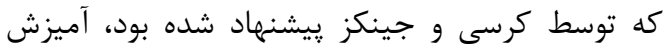

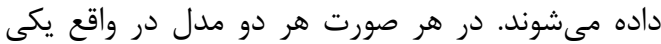

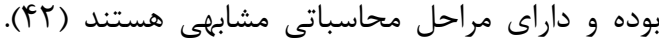

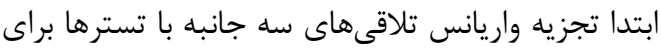

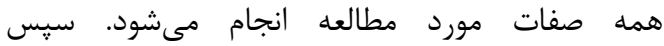

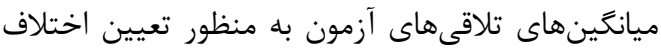

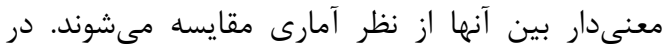

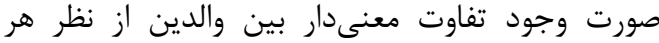

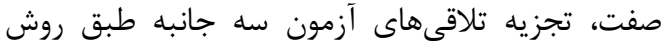

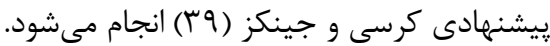

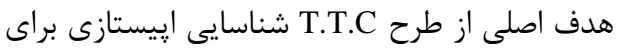

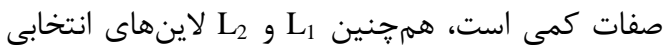

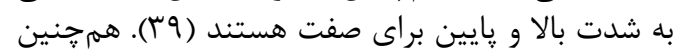

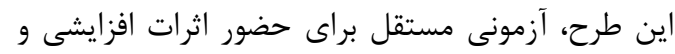

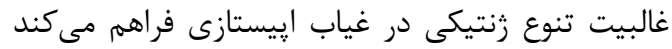

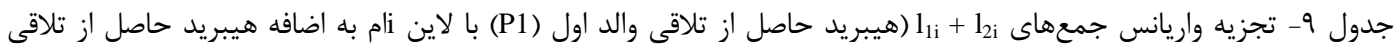

\begin{tabular}{|c|c|c|c|}
\hline & & \multicolumn{2}{|c|}{ والد دوم (P2) با لاين iام): } \\
\hline منابع تغييرات & درجه آزادى & ميانكين مربعات & اميد رياضى اجزاى واريانس \\
\hline تكرار & $r-1$ & $\mathrm{MSr}$ & . \\
\hline لاينها (جمع ها) & $\mathrm{n}-1$ & MSs & $\sigma_{e}^{2}+2 r \sigma_{s}^{2}$ \\
\hline خطا & $(\mathrm{n}-1) \times(\mathrm{r}-1)$ & MSe & $\sigma_{\mathrm{e}}^{2}$ \\
\hline
\end{tabular}

$\mathrm{r}=$ replication, $\mathrm{n}=$ genotype.

جدول • •- تجزيه واريانس جمعهاى

\begin{tabular}{|c|c|c|c|}
\hline منابع تغييرات & درجه آزادى & ميانكين مربعات & اميد رياضى اجزاى واريانس \\
\hline تكرار & $\mathrm{K}-1$ & $\mathrm{MSr}$ & - \\
\hline لاينها (تفاوتها) & $n-1$ & MSd & $\sigma_{e}^{2}+2 r \sigma_{d}^{2}$ \\
\hline خطا & $(\mathrm{n}-1) \times(\mathrm{r}-1)$ & MSe & $\sigma^{2}{ }_{e}$ \\
\hline
\end{tabular}




$$
\begin{array}{cc}
\sigma_{\mathrm{S}}^{2}=\frac{M s_{\mathrm{S}}-M s_{\mathrm{e}}}{2 \mathrm{r}} & \sigma_{\mathrm{S}}^{2}=\frac{1}{8} \mathrm{D} \\
\sigma_{\mathrm{d}}^{2}=\frac{M \mathrm{Md}^{-M s_{\mathrm{e}}}}{2 \mathrm{r}} & \sigma_{\mathrm{D}}^{2}=\frac{1}{8} \mathrm{H}
\end{array}
$$

$$
\text { كه عبارتست از واريانس جمعهاى } \sigma_{\text {S }}^{2}
$$

داراى اهميت بيشترى از اجزاى غالبيت بودند. آنها ماريا

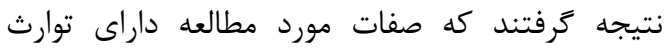

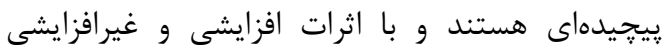

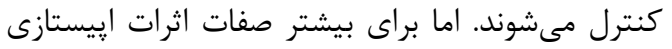

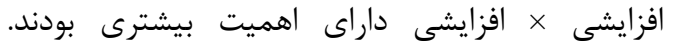

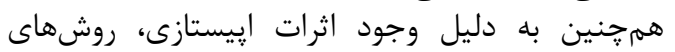

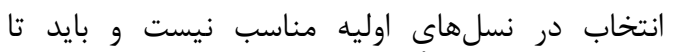

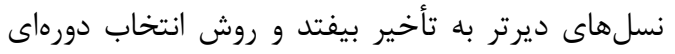

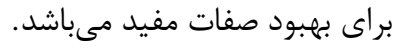

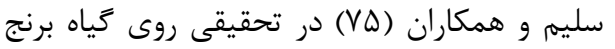

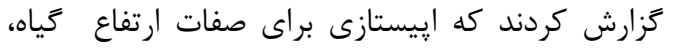

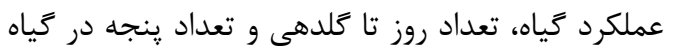

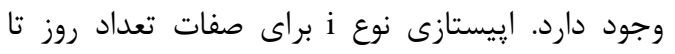

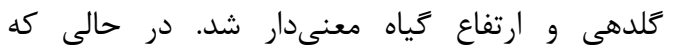

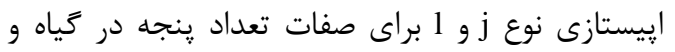

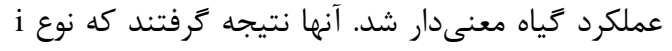

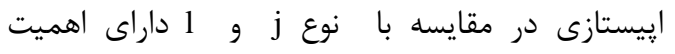
بيشترى است.

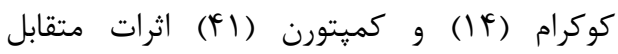

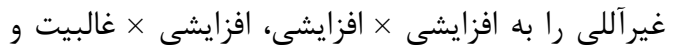

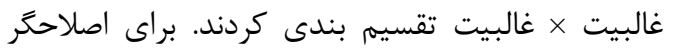

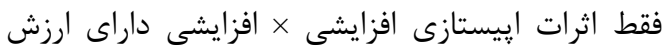

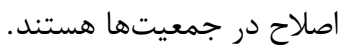

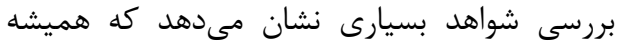

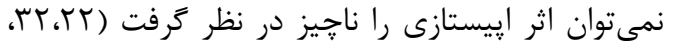

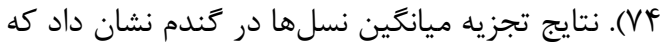

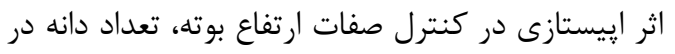

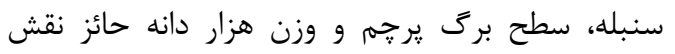

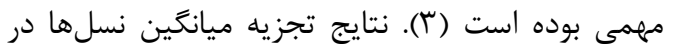

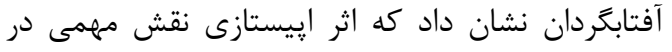

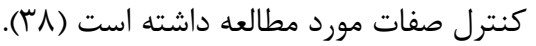

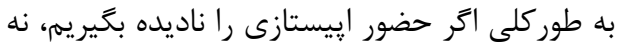

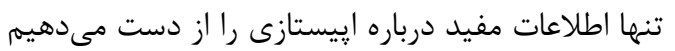

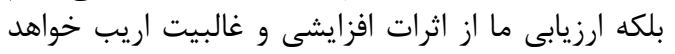

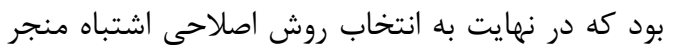
مى شود.
بر آورد جزء غالبيت (H)

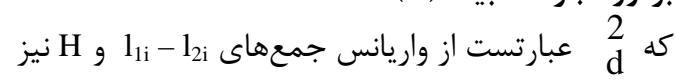
برابر است با جزء غالبيت.

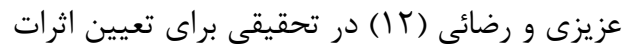

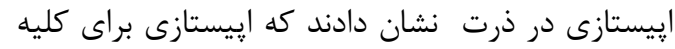

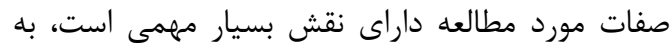

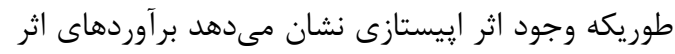

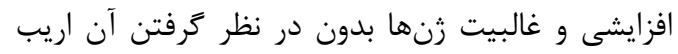

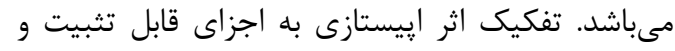

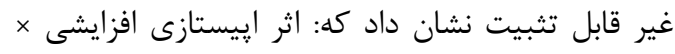

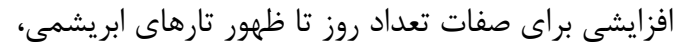

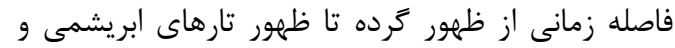

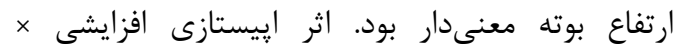

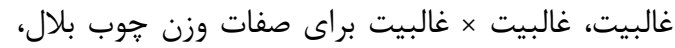

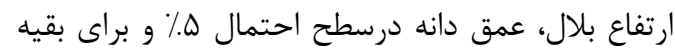

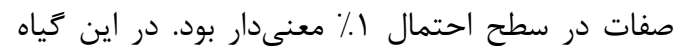

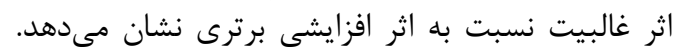

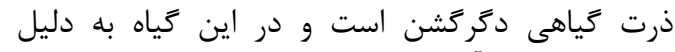

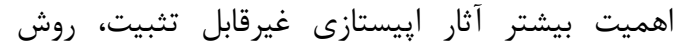

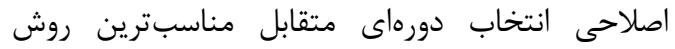

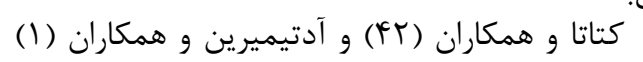

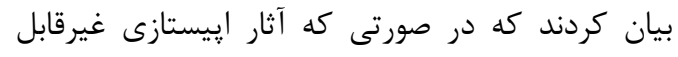

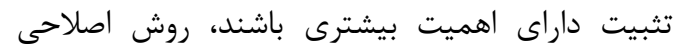

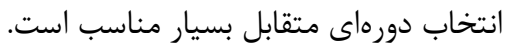

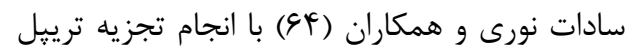

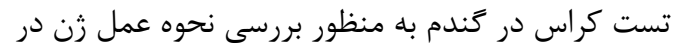

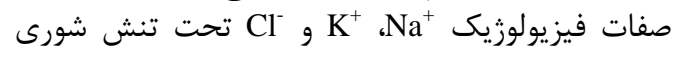

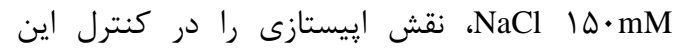

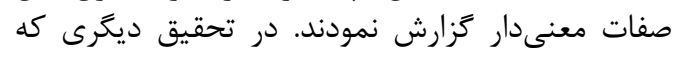

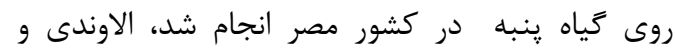

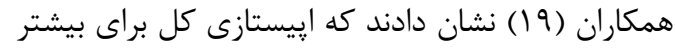

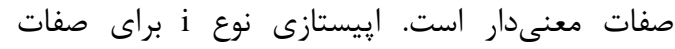

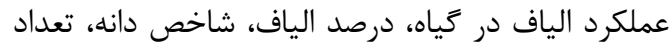

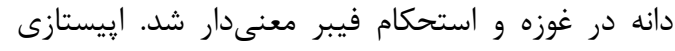

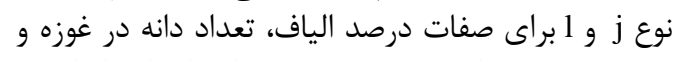

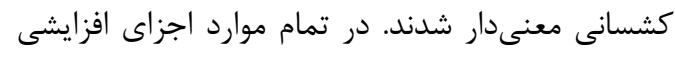


بنابراين حضور إيستازى، توارث صفات ارتفاع كياه،

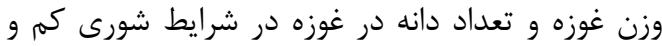

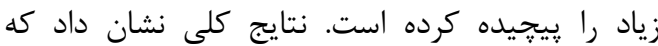

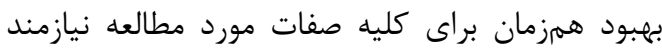

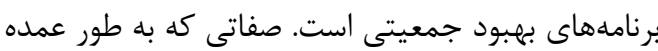

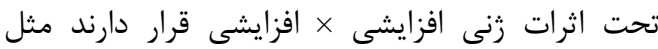

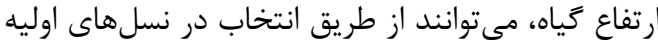

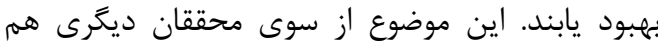

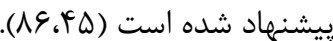

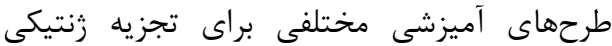

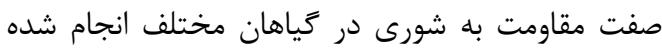

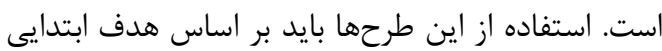

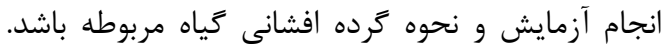

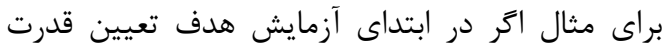

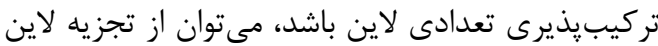

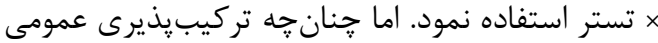

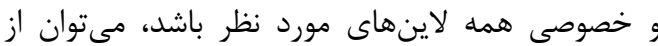

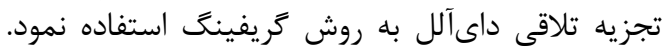

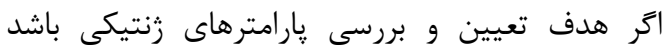

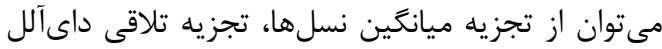

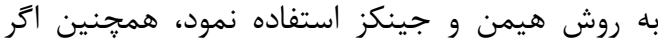

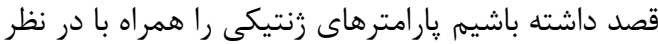

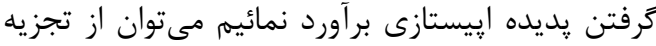

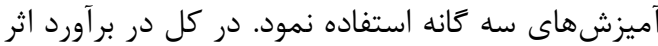

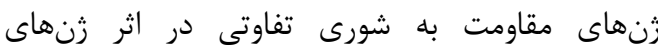

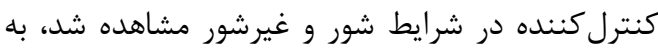

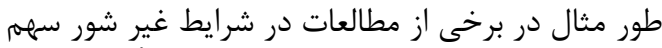

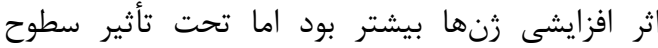

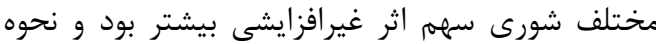

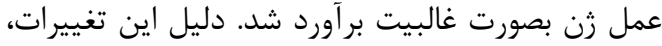

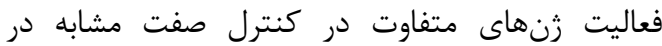

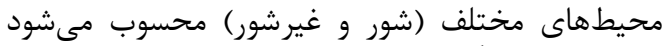

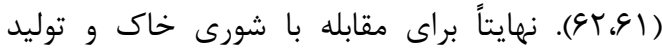

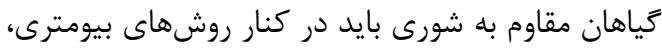

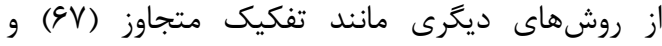

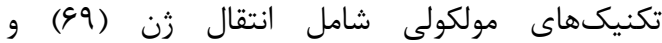

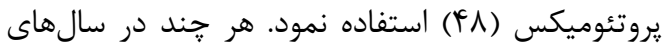

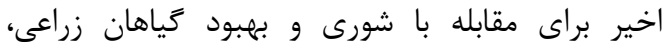

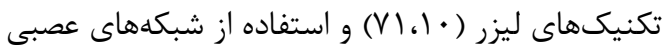

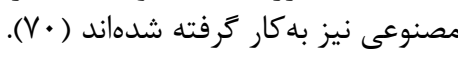

تركيب آزمايشى سهكانه تحت تنش شورى:

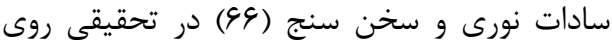

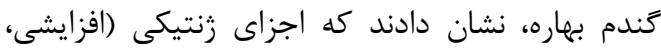

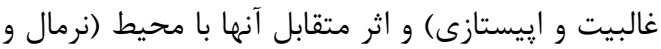

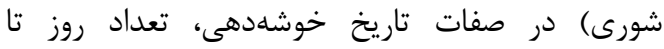

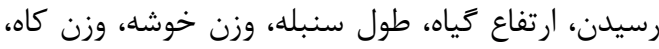

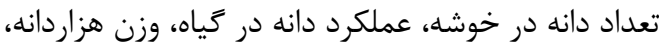

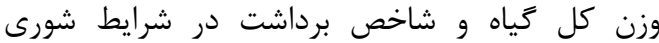

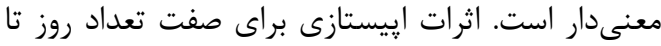

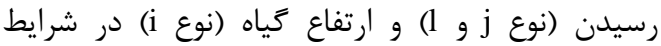

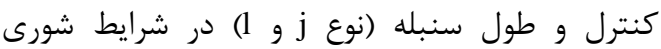

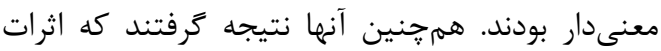

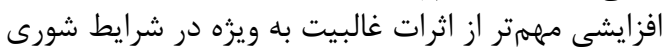

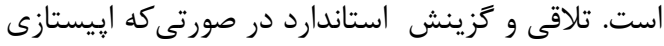

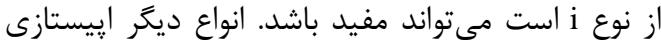

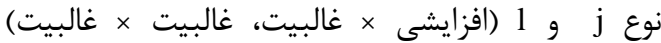

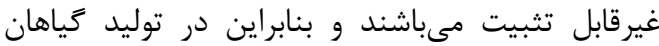

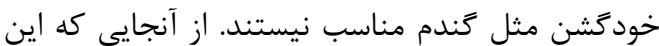

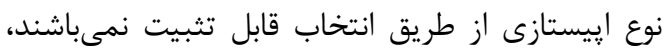

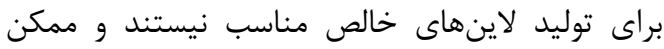

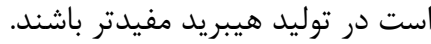

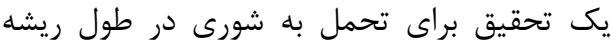

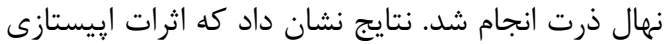

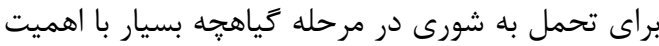

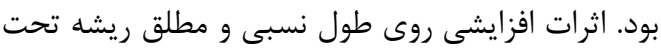

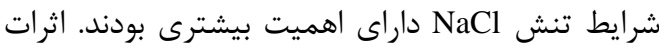

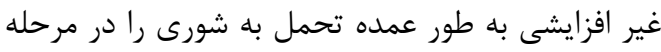

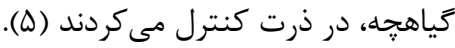

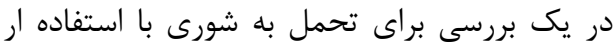

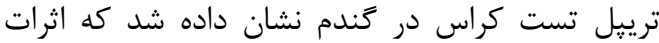

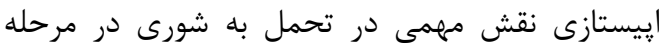

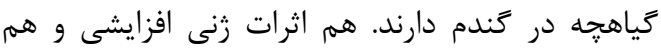

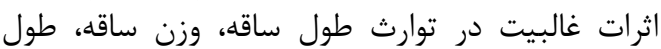

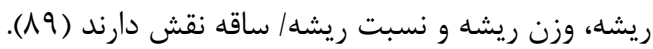

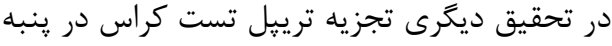

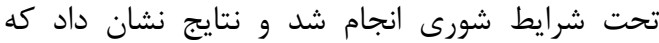

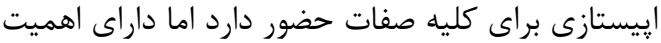

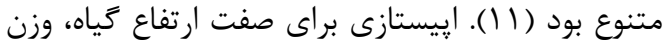

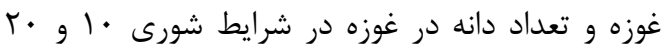

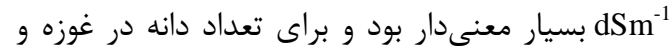

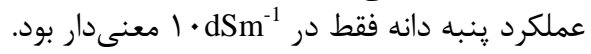


rᄉ مرورى بر روش هاى بيومترى براى اصلاح مقاومت به شورى در زياهان زراعى .

1. Adetimirin, V.O., M.E. Aken Ova and S.K. Kim. 2001. Detection of epistasis for horizontal resistance to striga bermonthica in maize. Maydica, 46: 27-34.

2. Akbar, M. and T. Yabuno. 1977. Breeding saline- resistant varieties of rice. IV. Inheritance of delayed type panicle sterility induced by salinity. Japanease Journal of Breeding, 27: 237-240

3. Akhtar, N. and M.A. Chowdhry. 2006. Genetic analysis of yield and some other quantitative traits in bread wheat. International Journal of Agriculture and Biology, 4: 523-527.

4. Ali Rao, S. and T. McNeilly. 1999. Genetic basis of variation for salt tolerance in maize (Zea mays L.). Euphytica, 108: 145-150.

5. Ali Khan, A. and T. McNeilly. 2005. Triple Test Cross analysis for salinity tolerance based upon seedling root length in maize (Zea mays L.). Breeding Science, 55: 321-325.

6. Allakhverdiev, S.I., A. Sakamoto, Y. Nishiyama, M. Inaba and N. Murata. 2000. Ionic and osmotic effects of NaCl- induced inactivation of photosystems I and II in Synechococcus sp. Plant Physiology, 123: $1047-1056$.

7. Allard, R.W. 1960. Principles of plant breeding. $2^{\text {nd }}$ edn, John Wily and Sons, Inc. New York, USA, $264 \mathrm{pp}$.

8. Ashan, M., D. Wright and D.S. Vrik. 1996. Genetic analysis of salt tolerance in spring wheat (Triticum aestivum L.). Cereal Research Communications, 24: 353-360.

9. Ashraf, M. 1998. Components of genetic variation of salt tolerance in (pigeon pea L., Mill sp.) Archives of Agronomy and Soil Science, 43: 409-416.

10. Ashrafijou, M., S.A. Sadat Noori, A. Izadi Darbandi and S. Saghafi. 2010. Effect of salinity and radiation on proline accumulation in seeds of canola (Brassica napus L.). Plant, Soil and Environment, 56: 312-317.

11. Ashfaq Bhatti, M., F.M. Azhar, A.W. Alvi and M. Ayub. 2006. Triple test cross analysis of seed cotton (Gossypium hirsutum L.) yield and its components, grown in salinized conditions. International Journal of Agriculture \& Biology, 80: 820-823.

12. Azizi, F. and A. Rezaie. 2006. Epistasis Effects of Yield and some Morphological Traits in Maize by Triple Test cross. Seed and Plant Improvement Journal, 22: 237-247 (In Persian).

13. Chinnusamy, V., A. Jagendorf and J.K. Zhu. 2005. Understanding and Improving salt tolerance in plants. Crop Science, 45: 437-448.

14. Cockerham, C.C. 1954. An extension of concept of partitioning hereditary variances for analysis of covariances among relatives, when epistasis is present. Genetics, 39: 859-882.

15. Comstock, R.E. and H.F. Robinson. 1948. The components of genetic variance in populations of biparental progenies and their use in estimating the average degree of dominance. Biometrics, 4: 254266.

16. Dashti, H., M.R. Naghavi and A. Tajabadipoor. 2010. Genetics analysis of salinity tolerance in a bread wheat cross. Journal of Agricultural Science and Technology, 12: 347-356.

17. Deepa Sankar, P., N. Subbaraman and S. Lakshmi Narayanan. 2008. Heterosis, combining ability and gene action studies in tgms based rice hybrids under normal and salt affected environments. Indian Journal of Agricultural Research, 42: 177-182.

18. Dehdari, A., A. Rezai and S.A.M. Maibody. 2007. Genetic control of salt tolerance in wheat plants using generation means and variances analysis. Journal of Science and Technology of Agriculture and Natural Resource, Water and Soil Sience, 11:179-192 (In Persian).

19. El-Lawendy, M.M., Y.M. El-Mansy and M.E. Abd El-Salam. 2010. Determination of genetics components through triple test crosses in cotton. Journal of Agricultural Research. Kafer El-Sheikh University, 36: 240-258.

20. Farshadfar, E. 1998. Application of biometrical genetics in plant breeding. Volume I. Tagh-E-Boostan Publication, Iran, 528 pp (In Persian).

21. Fathi Saadabadi, M. and S. Tahmasebi. 2008. Estimation of genetic parameters for traits effective on earliness in cotton using diallel crosses. Seed and Plant Improvement Journal, 24: 501-513 (In Persian).

22. Fazel Najafabadi, M., M.R. Ghannadha, A.A. Zali and B. Yazdi Samadi. 2004. Genetic analysis of seedling characters in bread wheat. Proceedings of the $4^{\text {th }}$ international Crop Science Congress, 914916 pp, Brisbane, Australia.

23. Flowers, T.J. and D. Dalmond. 1992. Protein synthesis in halophytes-the influence of potassium, sodium and magnesium in vitro. Plant and Soil, 146: 153-161.

24. Flowers, T.J. and A.R. Yeo. 1995. Breeding for salinity resistance in crop plants-where next? Australian Journal of Plant Physiology, 22: 875-884.

25. Flower, T.J., A. Garcia, M. Koyama and A.R. Yeo. 1997. Breeding for salt tolerance in crop plants the role of Molecular Biology. Acta Physiologiae Plantarum, 19: 427-433.

26. Flower, T.J. 2004. Improving Crop Salt Tolerance. Journal of Experimental Botany, 55: 307-319.

27. Foolad, M.R. 1996. Genetic analysis of salt tolerance during vegetative growth in tomato, Lycopersicon esculentum. Mill. Plant Breeding, 115: 245-250.

28. Ghannadha, M.R. 1998. Gene action for latent period of stripe rust in five cultivars of wheat. Iranian Journal of Crop Sciences, 1: 53-71 (In Persian).

29. Griffing, B. 1956. Concepts of general and specific combining ability in relative to diallel crossing systems. Australian Journal of Biological Sciences, 9: 463-493.

30. Hallauer, A.R. and F.O.J.B. Miranda. 1985. Quantitative genetics in maize breeding. Iowa State University Press, Ames Iowa, $275 \mathrm{pp}$.

31. Hayman, B.Y. 1954. The theory and analysis of diallel crosses. Genetics, 39: 789-809.

32. Hinze, L.L. and K.R. Lamkey. 2003. Absence of epistasis for grain yield in elite maize hybrids. Crop Science, 43: 46-56. 
33. Huang, J. and R.E. Redmann. 1995. Salt tolerance of hordeum and brassica species during germination and early seeding growth. Canadian Journal of Plant Science, 75: 815-819.

34. Ikram, U.H., A.K. Asif, F.M. Azhar and U. Ehsan. 2010. Genetic basic of variation for salinity tolerance in Okra (Abelmoschus esculentus L.). Pakistan Journal of Botany, 42: 1567-1581.

35. Jinks, J.L. 1954. The analysis of continuous variation diallel crosses of Nicotina rustica varieties. Genetics, 41: 451-459.

36. Jinks, J.L. and J.M. Perkins. 1970. A general method of detecting additive, dominance and epistatic components of variation. III. F2 and back cross populations. Heredity, 25: 419-429.

37. Jones, M.P. and J.W. Stenhouse. 1984. Inheritance of salt tolerance in mangrove rice. International Rice Research Newsletter, 9: 1984-1989.

38. Jovanovic, D. and R. Marin Koric. 2006. Use of additive -dominance model in genetic analysis of some quantitative characteristics in sunflowers. $8^{\text {th }}$ Eucarpia Biometrics in Plant Breeding Section Meeting. Agric Conspec Science, 71: 54 pp.

39. Kearsey, M.J. and J.L. Jinks. 1968. A general method of detecting additive, dominance and epistatic variation for metrical traits. L. Theory Heredity, 23: 403-409.

40. Kearsey, M.J. and H.S. Pooni. 1998. The genetical analysis of quantitative traits. Chapman and Hall press. London England, $381 \mathrm{pp}$.

41. Kempthorne, O. 1955. The theoretical values of correlation between relatives in random mating populations Genetics, 40: 153-167.

42. Ketata, H., E.L. Smith, L.H. Edwards and R.W. Mc New. 1976. Detection of epistasis, additive and dominance variation in winter wheat (Triticum aestivum L. em Thell). Crop Science, 16:1-4.

43. Khan, A.A., T. Mc Neilly and F.M. Azhar. 2001. Stress tolerance in crop plants. (Review). International Journal of Agriculture and Biology, 3: 250-255.

44. Khattak, G.S.S., M.A. Haq, M. Ashraf, G.R. Tahir and E.U.K. Marwat. 2001. Detection of epistasis and estimation of additive and dominance components of genetic variation for synchrony in pod maturity in mungbean (Vigna radiata L. Wilczek). Field Crops Research, 72: 211-219.

45. Kumar, P.R. and T.S. Raveendran. 2001. Genetic evaluation of yield and yield components in upland cotton through triple test cross analysis. Indian Journal of Agricultural Sciences, 71: 62-64.

46. Lande, R. 1981. The minimum number of genes contributing to quantitative variation between and within populations. Genetics, 90: 541-553.

47. Lion, C. 1941. Responses of two species of tomatoes and the $F_{1}$ generation to sodium sulphate in the nutrient medium. Botanical Gazette, 103: 107-122.

48. Li, X., M.F. Yang, H. Chen, L.Q. Qu, F. Chen and S.H. Shen. 2010. Abscisic acid pretreatment enhances salt tolerance of rice seedlings: Proteomic evidence. Biochimica et Biophysica Acta (BBA)Proteins and Proteomics, 1804: 929-940.

49. Mahmood, T., G. Shabbir, M. Sarfraz, M. Sadiq, M.K. Bhatti, S.M. Mehdi, M. Jamil and G. Hassan. 2002. Combining ability studies in Rice (Oryza sativa L.) under salinized soil conditions. Asian Journal of Plant Sciences, 1: 88-90.

50. Mahmud, I. and H.S. Krammer. 1951. Segregation for yield, height and maturity following a soybean crose. Agronomy Journal, 43: 605-609.

51. Mather, K. 1949. Biometrical Genetics. Methuen London, 162 pp.

52. Mather, K. and J.L. Jinks. 1982. Biometrical genetics the study of continuous variation. Chapman and Hall London, $390 \mathrm{pp}$

53. Multize, D.K. and R.J. Baker. 1985. Evaluation of biometrical methods for estimation the number of genes 1-effect of sample size. Theoretical and Applied Genetics, 69: 553-558.

54. Murtaza, N., M. Kitaoka and G.M. Ali. 2005. Genetic differentiation of cotton cultivars by polyacrylamide gel electrophoresis. Journal of Central European Agriculture, 6: 69-76.

55. Nabi, G., F.M. Azhar and A.A. Khan. 2010. Genetic mechanisms controlling variation for salinity tolerance in upland cotton at Plant maturity. International Journal of Agriculture and Biology, 12: $521-526$

56. Narayana, K.K. and S.R. Sree Rangasamy. 1990. Genetics analysis for salt tolerance in rice. Rice Genetics II. Second International Rice Genetics Symposium Los Banos, Philippines, pp: 167-173.

57. Opsahl, B. 1956. The discrimination of interactions and linkage in continuous variation Biometrics, 10: 415-432.

58. Parida, A.K. and A.B. Das. 2005. Salt tolerance and salinity effects on plants. A review. Ecotoxicology and Environmental Safety, 60: 324-349.

59. Rauf, S., M. Shahzad, J.A. Teixeira da Silva and I.R. Noorka. 2012. Biomass partitioning and genetic analyses of salinity in sunflower (Helianthus annuus L.). Journal of Crop Science and Biotechnology, 15: 205-217.

60. Rehman, P.J. 1996. The effect of sodium cholorid on germination and the potassium and calcium contents of Acacia seeds. Seed Science and Technology, 25: 45-57.

61. Richards, R.A. 1978. Genetic analysis of drought stress response in rape seed (Brassica compestris and B. napus). I. Assessment of environments for maximum selection response in grain yield. Euphytica, 27: 609-615.

62. Rumbaugh, M.D., K.H. Asay and D.A. Johnson. 1984. Influence of drought stress on genetic variance of alfalfa and wheat grass seedling. Crop Science, 24: 297-303.

63. Sadat Noori, S.A. and T. McNeilly. 1999. Assessment of variability in salt tolerance in diploid Aegilops spp. Journal of Genetics and Breeding, 183-188.

64. Sadat Noori, S.A., T. McNeilly and J.C. Collins. 1999. The genetic architecture of salt tolerance in wheat. II. Physiological characters. Agricoltura Mediterranea, 129: 88-98.

65. Sadat Noori, S.A. and T. McNeilly. 2000. Assessment of variability in salt tolerance based on seedling growth in triticum durum desf. Genetic Resources and Crop Evolution, 47: 285-291. 
r. مرورى بر روشهاى بيومترى براى اصلاح مقاومت به شورى در كَياهان زراعى .

66. Sadat Noori, S.A. and A. Sokhansanj. 2004. Triple test cross analysis for genetic components of salinity tolerance in spring wheat. Journal of Sciences, Islamic Republic of Iran, 15: 13-19.

67. Sadat Noori, S.A. and M. Harati. 2005. Breeding for Salt-Resistance Using Transgressive Segregation in Spring Wheat. Journal of Sciences, Islamic Republic of Iran, 16: 217-222.

68. Sadat Noori, S.A., A. Roustaei and B. Foghi. 2006. Variability of salt tolerance for eleven traits in bread wheat grown in different saline conditions. Journal of agronomy, 5: 131-136.

69. Sadat Noori, S.A. and A. Sokhansanj. 2008. Wheat plants containing an osmotin gene show enhanced ability to produce roots at high NaCl concentration. Russian Journal of Plant Physiology, 55: 256-258.

70. Sadat Noori, S.A., M. Ebrahimi, J. Khazaei and H. Khalaj. 2011. Predicting yield of wheat genotypes at different salinity by artificial neural network. African Journal of Agricultural Research, 6: 26602675 .

71. Sadat Noori, S.A., L. Ferdosizadeh, A. Izadi-Darbandi, S.M.M. Mortazavian and S. Saghafi. 2011. Effects of Salinity and Laser Radiation on Proline Accumulation in Seeds of Spring Wheat. Journal of Plant Physiology and Breeding, 1: 11-20.

72. Sadrabady, R., H. Marashi and M. Naseeri. 1996. Principles of cultivar development (Tranlate), Ferdowsi University Press, $554 \mathrm{pp}$ (In Persian).

73. Saeed, A., M.Q. Shahid, S.A. Anjum, A.A. Khan, A. Shakeel, M.F. Saleem and N. Saeed. 2011. Genetic analysis of $\mathrm{NaCl}$ tolerance in tomato. Genetics and Molecular Research, 10: 1754-1776.

74. Saha Ray, P.K., D. Hillerislambers and N.M. Tepora. 1994. Genetics of stem elongation ability in rice (Oryza sativa L.). Euphytica, 14: 137-141.

75. Saleem, M.Y., B.M. Atta, A.A. Cheema, Z. Mukhtar and M. Ahsanul Haq. 2005. Detection of epistasis and estimation of additive and dominance components of genetic variation using triple test cross analysis in rice (Oryza sativa, L). Caderno de Pesquisa Ser. Bio. Santa Cruz do Sul, 17: 37-50.

76. Saranga, Y., D. Zamir, A. Marani and J. Rudich. 1991. Breeding tomatoes for salt tolerance- fieldevaluation of Lycopersicon germplasm for yield and dry matter production. Journal of the American Society for Horticultural Science, 116: 1067-1071.

77. Sharifi, P., M.R. Safari Motlagh and H. Aminpanah. 2012. Diallel analysis for salinity tolerance in rice traits at germination stage. African Journal of Biotechnology, 11: 3276-3283.

78. Sharma, S., R.S. Sain and R.K. Sharma. 2003. Genetics of spike length in durum wheat. Euphytica. 130: $155-161$.

79. Singh, K.N. and R. Chatrath. 1997. Combining ability studies in bread wheat (Triticum aestivum L.) under salt stress environments. Indian Journal of Genetics and Plant Breeding, 57:127-132.

80. Singh, R.F. and B.D. Chaudhary. 1999. Biometrical methods in quantitative genetics analysis. Kalyani Press. Ludhina, New Delhi India, 318 pp.

81. Singh, R.P. and S. Singh. 1992. Estimation of genetic parameters through generation mean analysis in bread wheat. Indian Journal of Genetics, 52: 369-375.

82. Sykes, S.R. 1992. The inheritance of salt exclusion in woody perennial fruit species. Plant and Soil, 146: $123-129$.

83. Tal, M. and M.C. Shannon. 1983. Salt tolerance in two wild relatives of the cultivated tomato: Responses of lycopersican esculentum, L.Cheesmani, L.Peruvianum, Solanum Pennelli and $\mathrm{F}_{1}$ hybrids of high salinity. Australian Journal of plant physiology, 10: 109-117.

84. Tester, N. and R. Davenport. 2003. $\mathrm{Na}^{+}$tolerance and $\mathrm{Na}^{+}$transport in higher plants. Annual of Botany, 91: 1-25.

85. Thomson, W.W. C.D. Faraday and J.W. Oross. 1988. Salt glands. In: Baker D.A. and J.L. Hall, (eds.). Solute transport in plant cells and tissues. 498-537 pp., Harlow: Longman Scientific and Technical Press, New York, USA.

86. Tripathi, I.D. and M. Singh. 1983. Triple test cross analysis in three barley populations under saline alkali soil conditions. Journal of Agricultural Science Combinatorial, 101: 317-321.

87. Warner, J.N. 1952. A method for estimating heritability. Agronomy Journal, 44: 427-430.

88. Warnock, D.F., D.W. Davis and G.R. Gingera. 1998. Inheritance of ear resistance to Europea, corn barer in Apache Sweet corn. Crop Science, 38: 1451-1457.

89. Zafar, M., A. Salam Khan, M.A. Chowdhry and M.A. Bhatti. 2008. Triple test cross analysis for salinity tolerance in wheat. Pakistan Journal of Agricultural Sciences, 45: 40-43.

90. Zhou, H.K., Y. Hayat, L.G. Fang, R.F. Guo, J.M. He and H.M. Xu. 2010. Analysis of genetics and genotype. Environment interaction effects for agronomic traits of rice in salt tolerance. Pakistan Journal of Botany, 42: 3239-3246.

91. Vihayan, K., S.P. Chakraborti, S.G. Doss, P.D. Ghosh and S. Ericisli. 2008. Combining Ability for Morphological and Biochemical Characters in Mulberry (Morus spp.) under Salinity Stress. International Journal of Industrial Entomology, 16: 1-8. 


\title{
A Review on Biometrical Methods used for Salt Tolerance Breeding in Crops
}

\author{
Mohsen Niazian ${ }^{1}$, Masoumeh No'mani ${ }^{2}$ and Seyyed Ahmad Sadat Noori ${ }^{3}$
}

\author{
1- Ph.D Students, College of Aboureihan, University of Tehran (Corresponding authors: mniazian@ut.ac.ir) \\ 2 and 3- Ph.D Students and Profossor, College of Aboureihan, University of Tehran \\ Received: July 8, $2013 \quad$ Accepted: July 26, 2014
}

\begin{abstract}
Salinity of water and soil resources is one of the most important problems of farming especially in arid and semi arid regions. Gradual soil salinity is an important issue in many regions of the world especially in Iran. Salinity is lead to reducing the growth and yield of crop productions. Plant breeders search for an appropriate breeding method to produce salt tolerance plants due to major problems that soil salinity causes for production. Selection of an appropriate breeding method is depends on breadth of information about genetical controller systems in desired trait. Identifying gens that cause resistance or tolerance and determining the effects of these gens during salinity stress is very important. There are several biometric methods that plant breeders used to investigate the genetics of plants. The most common methods (designs) used in plant breeding experiments are North Carolina, generation mean analysis, triple test cross method, diallel cross method and line $x$ tester analysis. In this study a review has been made to investigate the genetics of salinity tolerance in different crops. Moreover, the results of these analyses were reviewed according to their applied aspects.
\end{abstract}

Keywords: Diallel analysis, Line $\times$ tester analysis, Generation mean analysis, North Carolina designs, Tolerance to salinity, Triple test cross 